\title{
Coherencia y Trascendencia del EZLN
}

\author{
José M. Aranda Sánchez \\ Centro de Investigación en Ciencias Sociales \\ y Humanidades-UAEM
}

\begin{abstract}
Resumen: En este artículo, se propone un análisis del EZLN como movimiento social, a partir de dos categorías principales: la coherencia y la trascendencia del movimiento. La primera para conocer la dialéctica interna del mismo, y la trascendencia, en que se analiza su dialéctica hacia afuera. Para el análisis de la coherencia y la trascendencia, se descomponen éstas en las siguientes relaciones lógicas: 1) Relación de validez: que se establece entre la organización del EZLN y su identidad; 2) Relación de legitimidad: como resultado de la correlación entre organización y las demandas del movimiento; 3) Relación de eficiencia: que se logra con la interrelación de la organización con el desempeño logrado; 4) Relación de consistencia: que evalúa la vinculación de la identidad con las demandas; 5) Relación de estructuración: que se crea entre la identidad y el desempeño, y 6) Relación de efectividad: que se pondera con la relación entre las demandas y el desempeño.

Abstract: The aim of this paper is to analyze EZLN as a social movement, based on two major categories: coherence and transcendence of this movement. These categories had been discomposed in six logical relations: 1) validity: defined as the relationship that is established between the EZLN's organization and its identity; 2) legitimacy: as the result of the correlation between its' organization and movement's demand; 3) efficacy: performance; 4) consistence: to evaluate the link between identity and demands. 5) structure: to describe the relation between identity and its' performance, and 6) effective: to evaluate the relationship between its performance and demands.
\end{abstract}

\section{Introducción}

$\mathbf{E}$

1 levantamiento zapatista del 1 de enero de 1994, no sólo sacudió a la sociedad y la política en México sino que, debido a su resonancia y carácter posmoderno, tiene implicaciones para la teoría de los movimientos sociales. Se trata de un acontecimiento fundamental, que llegó a cambiar y significar un punto de ruptura en la historia reciente del país. El inesperado movimiento armado del EZLN desde su aparición y hasta nuestros días, no ha dejado de generar importantes transformaciones socio-políticas con nuevos planteamientos y propósitos claramente presentados tanto al poder político como a la sociedad civil. 
El alzamiento zapatista ha terminado con algunos de los mitos del país. La paz social volaba por los aires, los gobernantes ya no eran tan infalibles, se denunciaba una democracia anémica en la prensa nacional e internacional y la pobreza made in México se exhibía por doquier con nombres y apellidos. Todo ello agudizaba las contradicciones del poder (Méndez y Cano, 1994: 278).

La guerra de Chiapas ha provocado el sacudimiento cultural y político más fuerte que haya sufrido el sistema mexicano en el último cuarto de siglo. Desde 1968 las estructuras del aparato político autoritario no habían sufrido una herida tan peligrosa. "Tanto en 1968 como en 1994, grupos sociales marginales -los estudiantes, los indígenas- sorpresivamente invaden el escenario y asumen el papel protagónico que otras fuerzas debían representar, según el libreto escrito por los demiurgos de la política" (Méndez y Cano, 1994: 11).

La frescura del movimiento zapatista se combinó con una serie de elementos que permitió a la sociedad mexicana apreciar lo que estaba ocurriendo: la inquietud por la conversión de parte del territorio nacional en un campo de batalla; la inminencia de un etnocidio; la autenticidad innegablemente comunitaria e indígena del movimiento zapatista; la justeza de las demandas presentadas en la Primera Declaración de la Selva Lacandona; el desgaste de la izquierda tradicional; $y$ la capacidad de los combatientes zapatistas para encarar valores como la dignidad y la coherencia política; movilizaron al actor que se convertiría desde entonces en el interlocutor por excelencia del zapatismo: la sociedad civil (Bertancourt, 1998: 88).

El propósito central de este trabajo, es analizar algunas de las posibles consecuencias que el movimiento zapatista en Chiapas pueda tener en la teoría de los movimientos sociales. En particular, se busca argumentar a favor del uso de dos categorías de análisis para estudiar los movimientos sociales: la coherencia y la trascendencia del movimiento. La primera, se analiza a partir de una descomposición de su contenido básico, en un conjunto de relaciones lógicas que dan cuenta de la validez, la legitimidad, eficiencia, consistencia, estructuración y efectividad del movimiento; en tanto que la trascedencia se pondera a partir de su propia influencia, la resonancia, las formas de comunicación y la fuerza de convocatoria.

La orientación teórica desde la que se busca la comprensión del proceso seguido por el EZLN corresponde a Melucci, específicamente en dos sentidos: cuando establece que el primer paso para estudiar un movimiento social es identificar el campo de conflictos dentro del que se inscribe la toma de acción por un grupo social; y en lo relativo a que 
los movimientos sociales contemporáneos plantean demandas de validez y alcance mundial, movimientos que funcionan más como redes de solidaridad, sistemas de acción social que definen su identidad en la praxis estructurante, atendiendo a necesidades radicales para cuya satisfacción se hace imprescindible un cambio histórico.

Asimismo, estas dos categorías buscan analizar al movimiento en dos dimensiones: la primera hacia dentro y la segunda hacia afuera, para dar cuenta de un movimiento social particular, a la vez que representa rasgos básicos de todo movimiento, es decir, incorporarse a la teoría de los movimientos sociales.

\section{Análisis de la coherencia y trascendencia del EZLN}

El panorama mundial de los actores sociales se ha transformado profundamente en las dos últimas décadas. Hasta los setenta, los problemas de la democracia y la participación se encontraban centrados en el sistema político: partidos políticos y elecciones para la transformación social democrática, guerras de liberación para las situaciones revolucionarias (Jelin, 1994: 101).

Sin embargo, desde finales de los setenta, asistimos al surgimiento de nuevos lenguajes, en un proceso creciente de modificación de los signos y símbolos de lo público, y nuevas formas de fundamentación de la presencia de los actores sociales en esa esfera de lo social.

Durante los años noventa, predomina en los movimientos sociales una composición social heterogénea, una organización basada en un liderazgo múltiple, una actitud abiertamente antiestatal, ofreciendo por ello mayor capacidad de participación autónoma como nuevos actores sociales, además de los cambios que representa para la sociedad civil (Muro, 1994: 46).

Dentro de las recientes aportaciones a la elaboración de la teoría de los movimientos sociales, cabe destacar los trabajos de Jelin (1994), Touraine (1992), y especialmente Melucci, en la línea de continuar profundizando y esclareciendo las características de los nuevos movimientos sociales; pero sobre todo con reflexiones que avanzan el análisis hacia una concepción de los movimientos como sistemas de acción social, y la constitución de sujetos y actores sociales que aparecen o reaparecen en la escena política con acciones concretas.

Particularmente importantes resultan los planteamientos de Melucci, para quien la acción colectiva actual presenta un discurso que 
anuncia los cambios posibles no en el futuro distante sino en el hoy aquí, donde los movimientos contemporáneos toman las formas de redes de solidaridad con poderosos significados culturales, lo que los distingue marcadamente de los actores políticos o de las organizaciones formales; $y$ en los cuales la identidad no es un dato o esencia, sino la resultante de "...intercambios, negociaciones, decisiones y conflictos entre diversos actores” (Melucci, 1998: 2-3).

Así, enfatiza cómo los procesos de movilización, los tipos de organización, los modelos de liderazgo, las ideologías y las formas de comunicación configuran niveles significativos de análisis para reconstituir, desde su interior, el sistema de acción social que define al actor colectivo, y sus nexos con el ambiente, particularmente con el sistema político, lo que condiciona las oportunidades y limitaciones dentro de las que el actor colectivo asume una presencia, la mantiene o la recompone (Melucci, 1998: 4).

A partir de que las formas de acción colectiva se han diversificado y aumentado considerablemente, y que tienen una función importante en distintos niveles del sistema social, Melucci plantea que el primer paso para poder analizar un movimiento social es identificar el campo de conflicto que se presenta en el sistema social y posteriormente explicar la forma y proceso en que diversos grupos sociales toman acción en ellos.

Se trata de analizar al zapatismo como movimiento social, que surge y responde a las condiciones impuestas por un campo de conflictos donde se origina el movimiento, y hacia el cual se toma una acción determinada; y asimismo llevar a cabo una diferenciación del zapatismo en cuanto a su coherencia y trascendencia como movimiento social, con base en un esquema analítico que permita examinar sus características fundamentales.

En primer lugar, en el caso que nos ocupa, el conflicto social que da sentido y significado al movimiento zapatista tiene tanta historia como la conquista española y la devastación de los indígenas por más de 500 años, y por lo tanto se trata de un conflicto complejo, enquistado en las entrañas de la estructura social y política, donde los pueblos indígenas han sido sometidos, saqueados, dominados, explotados y marginados de los escasos beneficios que el poder económico y político permite a los indígenas en un país capitalista subordinado como México. 
Sin pretender hacer un análisis detallado del conflicto chiapaneco en el que se inscribe la toma de acción del EZLN, se anotan algunos de sus rasgos principales, destacando los aspectos estructurales que acotaron un conjunto de opciones de participación, a la vez que se daba la constitución de actores sociales.

Perteneciente al llamado cinturón de pobreza, y con una composición étnica rica y variada, Chiapas ha sido objeto de un brutal nivel de explotación y opresión. A contrapie del país que se vendía al TLC, el país real daba su cara en Chiapas, ya que el proyecto neoliberal condena a amplias regiones del país a condiciones de subdesarrollo típicas de las peores regiones del tercer mundo. Chiapas es un estado rico por sus recursos naturales (energía eléctrica, petróleo, madera), pero mueren 15 mil personas anualmente debido a enfermedades originadas por la pobreza. El $58.3 \%$ de la población vive en zonas rurales; $30 \%$ de la población mayor de 15 años es analfabeta; $36.7 \%$ de la población mayor de 5 años no habla español; tan sólo $58 \%$ de las viviendas cuentan con agua potable, apenas $66.9 \%$ tienen energía eléctrica; únicamente $0.60 \%$ del crédito nacional es destinado al estado (cuando el promedio nacional es de 6.48\%) (Tiguera, 1995: 46-47).

Las condiciones materiales de las regiones en Los Altos y la Selva en Chiapas son, a excepción de San Cristóbal de las Casas, de pobreza y pobreza extrema, es decir, de alta y muy alta marginalidad. En contraste con ellas existen pequeños grupos empresariales, finqueros, ganaderos e intermediarios con altos niveles de ingreso, cuyo mejoramiento ha estado en todo momento ligado con las autoridades gubernamentales, tanto federales como de la entidad (Rodríguez, 1997: 369).

Según cifras de los conteos de 1995, Chiapas era el estado número uno en marginación, y los municipios de Los Altos y la Selva son, en su mayoría, de muy alta marginación, lo que significa mayor despojo y explotación a manos de madereros, cafeticultores, ganaderos y finqueros (COESPO, 1998). Decenas de miles de indios no tienen gas, electricidad, petróleo, su alimentación se compone de maíz con agua, muy rara ocasión comen carne y en la mayoría de los municipios su ingreso diario, por jornada de sol a sol, no es mayor a 60 centavos de dólar, para mantener una familia de cinco integrantes en promedio (Rodríguez, 1997: 370). 
En medio de esa pobreza generalizada, Chiapas también ocupa el primer lugar en muerte por desnutrición $(77 \%$ de los niños padece desnutrición), estimándose que solamente en 1993 murieron 15 mil personas por enfermedades curables, sobre todo gastrointestinales.

Asimismo, en Chiapas se concentra más del 25\% del rezago agrario nacional, y las tres cuartas partes de la tierra son de propiedad privada, representando más de la tercera parte de la superficie total del estado (Rodríguez, 1997: 370).

Y por si fuera poca cosa tanta violencia: de las guardias blancas, el despotismo de los gobernadores, los fraudes y manipulaciones políticas, la depredación de sus recursos naturales y muchas otras formas de discriminación y maltrato a los indios, el gobierno federal determinó que la reforma agraria había concluido, es decir, que no había más tierras que repartir entre los campesinos. La reforma al artículo 27 de la Constitución incendió el ánimo de las comunidades, ya que fue la puerta que se les cerró a los indígenas para poder sobrevivir en forma pacífica y legal. "Los indígenas protestaban, intentaban trámites en las oficinas de gobierno, denunciaban atropellos, invasiones de tierras y asesinatos a su gentes que nunca fueron siquiera investigados, pero nadie los oía ni los veía" (Rodríguez, 1997: 370).

Se trata de dos niveles en que se presenta el conficto: un conflicto estructural, dentro del sistema social, donde el poder político y económico ha sometido, explotado, segregado y fragmentado a la sociedad civil del país; y un conflicto particular, exacerbado por el neoliberalismo y su proyecto de modernidad que no representa ningún futuro para millones de seres humanos, y el cual está siendo aplicado indistintamente en la mayoría de los países latinoamericanos, en donde Chiapas se perfilaba como parte del eslabón más débil de la cadena que nos tiene sujetados.

Como conflicto en el sistema, se refiere a una tensión, un desequilibrio que puede asumir valores y proporciones críticas hasta poner en peligro al sistema mismo, exigiendo cada vez más recursos coercitivos para lograr el control, es decir, puede hablarse ya de una disfunción del sistema, en la medida que al no lograr que los contrarios de la tensión disminuyan sus desigualdades y exigencias, se trastoque el ritmo de interacciones, se rompa la relación entre gobernantes y 
gobernados, y se inicie un periodo de cambios, que pueden incluir la violencia y el surgimiento de nuevos actores políticos.

En tanto conflicto particular, una cuestión central es que los contrarios, es decir, las partes conflictivas que definen sus intereses como antagónicos, e incluso llevan la confrontación hasta la lucha armada, abren su participación con una identidad que represente su parte en el conflicto: por un lado el que alzó la voz y las armas, por el otro el ejército federal, garante de la seguridad nacional. El conflicto, entonces, se inició por la parte más radical del conflicto estructural en el sistema: por el punto donde éste mantiene su poder y fuerza coercitiva, es decir, el conflicto social y político chiapaneco se conectó al conflicto nacional que nos arrastra hacia la disolución de la sociedad mexicana, una vez que se agotaron todos los caminos y procedimientos legales y pacíficos para hacer valer los derechos elementales de sobrevivencia rural.

Puede decirse que el recurso de las armas parecía inevitable, la única forma de salir-entrando al conflicto; aunque la cuestión era la viabilidad de una lucha armada. Al recurrir a las armas, los zapatistas abrieron una coyuntura en México, reabriendo además el debate acerca de la posibilidad y necesidad de un cambio revolucionario en el país; pero, sobre todo, entrando de lleno al conflicto y tomando acción. El levantamiento sacudió la conciencia de la sociedad; puso fin al triunfalismo del gobierno; situó sin equívocos al principio de las prioridades del país el problema de la marginación y de la pobreza; contribuyó también, junto con otros factores, a presionar a favor de la transición a la democracia (Tello, 1995: 208).

Como el propio conflicto del cual surge, y en las condiciones concretas de una rebelión indígena por el antipoder, las consecuencias del mismo fueron contradictorias en Chiapas y en el país, obligando a todos a la toma de acción, a "estallar el conflicto" en la sociedad y en cada uno de los mexicanos, a desbordar las ataduras que el poder y el capital nos han impuesto, y en su lugar oponer la ética como política y la democracia como camino.

Una vez que se ha identificado el campo de conflictos dentro del que surge el zapatismo, pasemos al análisis de la coherencia y trascendencia del EZLN, en la perspectiva de reflexionar las consecuencias que derivan en la construcción de la teoría de los movimientos sociales. 
Para determinar la coherencia del movimiento zapatista, se examinarán las siguientes relaciones lógicas entre los componentes o partes del proceso seguido por el EZLN, y que en su compleja interrelación dan cuenta del encadenamiento, unión, sentido y razón del movimiento social:

1. Relación de validez: que se establece entre la organización del EZLN y su identidad.

2. Relación de legitimidad: planteada como resultado de la correlación entre la organización y las demandas del movimiento.

3. Relación de eficiencia: que se logra cuando se considera la interrelación de la organización con el desempeño logrado.

4. Relación de consistencia: que se evalúa al vincular la identidad con las demandas.

5. Relación de estructuración: que se crea entre la identidad y el desempeño.

6. Relación de efectividad: que se pondera con la relación entre las demandas y el desempeño.

En cuanto a la trascendencia del zapatismo, se analizará en términos de las movilizaciones que generó con su capacidad de convocatoria, la resonancia que alcanzó en el entorno, el impulso para el establecimiento de redes de solidaridad en la sociedad civil, las formas de comunicación empleadas, y en conjunto la influencia que ha logrado tener como sujeto social.

\section{Relación de validez}

Para observar la relación de validez del zapatismo, se procederá presentando en primer lugar los planteamientos fundamentales de su organización, enseguida de su identidad, y entonces se discernirá sobre la autenticidad del movimiento, de su valor como tal.

Organización. En este punto interesa resaltar básicamente dos aspectos: 1) que los componentes de toda organización social son de carácter psicosocial: papeles, normas y valores, donde los papeles describen las formas específicas de conducta asociadas con determinadas tareas. Los papeles son pautas estandarizadas de conducta que se piden a toda persona que desempeñe una tarea en una 
relación funcional dada, sin tener en cuenta sus deseos particulares o sus obligaciones interpersonales, cuando carezca de importancia para la relación funcional. Las normas son expectativas generales de carácter obligatorio para todos los que desempeñan un papel en un sistema o subsistema. Valores son las justificaciones y aspiraciones ideológicas más generalizadas, y 2) la organización, como estructura del movimiento social, establece las funciones a desempeñar por todos los integrantes, conformando una red de solidaridad, de vinculación psicosocial; a la vez que representa un conjunto práctico, en tanto que se constituye y actúa con propósitos de acción colectiva.

Para comprender la importancia y fortaleza de la organización del zapatismo, hay que tener en cuenta que es producto de la acumulación de experiencia colectiva y la formación de dirigentes propios durante al menos 20 años de pasar por organizaciones y movilizaciones de todo tipo. Incluso, Marcos afirmó en 1996 que el movimiento indígena, al cual el núcleo inicial del EZLN se sumó en 1984, se conformaba de dos vertientes: una, los indígenas en las comunidades; la otra, un grupo de dirigentes locales, unos cuantos, que eran los "intelectuales orgánicos de esos indígenas, políticos con gran capacidad organizativa, con una experiencia de lucha política muy rica, que estuvieron prácticamente en todas las organizaciones políticas de izquierda y conocieron todas las cárceles del país. Ellos se dan cuenta de que para sus problemas de tierra, de condiciones de vida y de derechos políticos no hay otra salida que la violencia" (citado por Gilly, 1997: 71).

La organización del EZLN presenta características fundamentales como movimiento social, ya que aparece tanto como una organización político-militar con férrea disciplina, normas, valores y papeles claramente definidos y jerarquizados; y asimismo como una forma de organización indígena basada en la democracia participativa de las comunidades que se constituyen como sujeto social, tomando acción particular en un conflicto dentro del cual adquiere significado su acción.

En el primer sentido, el EZLN se estructura con una cabeza o centro de mando en el llamado Comité Clandestino Revolucionario Indígena (CCRI), que es la Comandancia General del Ejército Zapatista, cumpliendo funciones de jerarquía militar, específicamente con la misión de reducir la fortaleza militar y política del enemigo, el Estado, a la par con un aumento de su potencial ofensivo, hasta el punto que la 
fuerza guerrillera pueda organizar y conformarse como ejército regular, con capacidad para combatir y vencer al gobierno (Huerta, 1998: 61).

El Comité Clandestino se compone por decenas de representantes, participando en él dos delegados nombrados por cada uno de los comités que controlan un territorio. Esta comandancia general zapatista fue la que tomó la decisión de iniciar la guerra, de impulsar un cambio revolucionario, de transformar la sociedad para lograr justicia.

Se habla de que la fortaleza táctica principal de la comandancia general radica en su gran conocimiento de las comunidades de base y del territorio en donde se asientan éstas, a tal grado que se ha convertido en zona de control del zapatismo. Las tácticas de lucha corresponden a las condiciones sociales predominantes, a las potencialidades de los guerrilleros combatientes, a las condiciones del terreno, así como a los objetivos de combate. Las acciones más importantes han sido ataques sorpresivos, emboscadas y sabotajes, y asaltos para obtener transportes, explosivos y otros requerimientos, en su mayoría de propiedad pública.

La Comandancia General al ejercer la función básica de liderazgo de la organización, le ha dado a ésta la posibilidad de convocar a la sociedad para luchar por cambiar el malestar social, buscando aglutinar a toda la población inconforme bajo la bandera política del levantamiento popular, a fin de ganarse el apoyo y la simpatía, así como la legitimidad ante la sociedad civil en su conjunto.

La Comandancia General, como eje de la organización zapatista, tiene a su cargo los dos grandes conjuntos de acciones que la han caracterizado: acciones militares y acciones de comunicación. En otro apartado examinaremos su desempeño y resultado de las mismas. Por el momento, lo que interesa resaltar es la función central de la organización, tanto por la estructura que presenta, como debido a que con base en su organización es que el movimiento zapatista ha logrado no sólo cumplir sus tareas y objetivos, sino además trascender y generar una resonancia nunca antes conocida en México y en otras partes del mundo.

La Subcomandancia, ubicada militarmente como mando medio en el esquema de un ejército regular, tiene como responsabilidad encabezar todos los combates militares; y en el caso del EZLN, fungir como representantes y voceros del movimiento ante la sociedad y la 
opinión pública nacional e internacional. La Subcomandancia del EZLN cumple la importante función de ser la instancia ejecutora de las acciones decididas y ordenadas por la Comandancia General, tanto en lo militar como en las tareas de comunicación (Huerta, 1998: 63).

En seguida, están los mandos integrados por tenientes y subtenientes, y de ahí hasta la tropa. Sin duda la flexibilidad de las estructuras del EZLN favorecía que sus dirigentes aprovecharan, en su totalidad, el apoyo que recibían de las comunidades de la Selva. En esas estructuras, abajo de los insurgentes, había reclutas, milicianos y bases de apoyo. Los primeros estaban dedicados a la causa; los segundos participaban en ella; los terceros, a su vez, les brindaban su protección (Tello, 1995: 108-109). En la organización del EZLN, la tropa ocupa un sitio especial, formada en su mayoría por miles de indígenas de los grupos tzeltales, tzotziles y otras etnias, con la función de soldados combatientes.

Sin embargo, el ejército zapatista se ostenta como fuerza alternativa, que representa lo que el ejército federal no ha podido hacer, ya que con su sola existencia cuestiona de facto la institución que, siendo irónicamente el aparato represivo del Estado, ha pretendido no obstante reflejar y convertirse en depositaria de la imagen emotiva de la nacionalidad, el patriotismo y la heroicidad. Entonces, la existencia de un ejército distinto del federal, representa un desafío frontal y total al monopolio simbólico ejercido desde hace ochenta años por un Estado que se presenta como heredero directo de la revolución de 1910.

En el segundo sentido, la organización zapatista, en la medida que abarca comunidades completas y lleva a cabo acciones de ocupación territorial con su influencia, significa el surgimiento de una forma de poder popular, y no sólo una guerrilla que se apoya en una milicia, a la vez que la organización comunitaria se entrelaza con el ejército rebelde (Machuca, 1998: 43).

La ocupación zapatista de los territorios, ha significado el aporte y esfuerzo vivo de hombres y mujeres, provenientes de diferentes grupos étnicos que han construido espacios estratégicos de importancia simbólica que contribuyen a configurar una legitimidad territorial (Machuca, 1998: 44).

Pero las referencias a formas de organización social distintas a las que ha impuesto el capital les da la posibilidad a los zapatistas de pensar en la historicidad de los procesos y, en consecuencia, en su 
carácter temporal, perecedero."Es ésta una de las grandes aportaciones que provienen de la cultura ancestral de las comunidades indígenas y es lo que les da la determinación de construir un mundo nuevo deconstruyendo el mundo del capital" (Ceceña, 1998: 144).

Identidad del EZLN. La relevancia del tema de la identidad radica en el hecho de que ella es condición imprescindible para la conformación de un sujeto capaz de incidir en las estructuras del poder establecido. El contenido del discurso de la identidad es a la vez ético y político ya que interroga acerca de la posibilidad y conveniencia de una sociedad multicultural y multiétnica. La identidad, como una representación estructurada del ser, llevada a cabo en su positivo por el ojo estrecho de lo negativo, es siempre un efecto temporal e inestable de relaciones que la definen haciendo diferencias. El énfasis está en la multiplicidad de identidades y diferencias, lo que da lugar a la necesidad de dejar atrás cualquier resquicio de opresión y resistencia.

En cuanto a la identidad del EZLN, ésta se encuentra estrechamente vinculada con dos categorías centrales: la historia o en todo caso la lucha por la historia; y la definición del sujeto del movimiento como búsqueda de una respuesta fundamental a la pregunta de ¿quiénes somos?, o sea, ¿quién es ese sujeto social que enfrenta, y cuestiona al Estado? Para encararse con el enemigo era impostergable esclarecer el ¿quiénes somos?, para entonces sí saber quién es el otro al que nos dirigimos.

Difícilmente podría comprenderse la forma en que se construye la identidad del EZLN sin hacer referencia a la historia, en la medida que es la fuente del discurso en el cual se exponen las razones y el lugar desde el que se enuncia el ser del movimiento. La historia tiene un rol esencial en los planteamientos del EZLN, tanto en lo relativo a la legitimación de la lucha por su rasgo milenario, como por su contribución en la construcción de la identidad étnica (Rojo, 1996: 327).

Así, la permanencia en el tiempo permite encontrar lazos entre el pasado y el presente, el relato histórico-biográfico va configurando la comunidad imaginaria, reforzando los lazos y sentimientos de pertenencia, de identificación que generan la coherencia, tanto de la comunidad de base del movimiento, como de su propio comportamiento como sujeto social (Rojo, 1996: 327). 
La identidad indígena, afirmada por la experiencia y la práctica del movimiento aparece como organizadora de la comunidad y determinadora de sus relaciones con los gobiernos federal y estatal. En realidad, esta identidad en positivo es una respuesta política a la exclusión de los indígenas como tales, rechazados de sus derechos como ciudadanos mexicanos. "Los indígenas, al quedar excluidos de ese pacto, fueron llevados a afirmar su propia identidad para poder subsistir, resistir y persistir. La línea divisoria había sido trazada desde el otro lado" (Gilly, 1997: 68).

El rescate del pasado -base de la identidad- parece conferirle legitimidad a las luchas presentes y orientación a la lucha por los cambios. Esa intención de formular la identidad en la historia nacional expresa una forma reclamada de integración a la patria, de ahí que aparezcan autoidentificaciones de los miembros del EZLN como los "sin rostro, los sin voz", los "más humildes de la tierra", y otras, que muestran el lugar desde el cual se presenta la definición del sujeto social, por lo que el olvido, la marginación y, finalmente, el sacrificio son elementos de identificación que se desprenden de esa compleja y ancestral relación y representación social.

La afirmación de la identidad apareció desde los primeros momentos del levantamiento “...Somos miles de indígenas alzados en armas, detrás de nosotros hay decenas de miles de familiares nuestros..." (EZLN. Documentos y comunicados, 1996: 74).

En el mismo sentido, las identificaciones étnicas y comunitarias aparacen como prioritarias en todo el discurso zapatista, pero como parte constitutiva de la patria, por lo que se trata de eliminar los obstáculos de todo tipo que han funcionado para no considerarlos dentro de la misma.

Para comprender la importancia y significado de la afirmación de identidad del EZLN, hay que tener en cuenta que ésta se reclama como fundamento para acceder a la plena ciudadanía (el derecho a tener derechos) con características comunes a toda la nación, más que étnicas. Lo que sucede es que la extensión de sus demandas y la interrelación de su problemática particular con los grandes problemas nacionales, sobre todo con la falta de libertad, democracia y justicia, dentro de los que se encuentra el debate por la autodeterminación indígena, posibilitaron crear un vínculo no contradictorio entre las 
demandas étnicas y las reivindicaciones ciudadanas de alcance nacional (Rojo, 1996: 328).

Otro de los aspectos relevantes de la identidad, es la necesidad de legitimación histórica, en el sentido de presentar su lucha como continuidad con las luchas "heróicas" de la historia de México, lo que promueve la búsqueda de orígenes, de "padres fundadores", de los cuales sentirse sucesores naturales. Por ello, la exigencia del EZLN es para negar la muerte histórica que significa el olvido; para recuperar la historia que afirma la legitimidad social como pueblo, reclamando el derecho a continuar siendo, porque se es producto de la historia. Pero cuando el monopolio de la historia oficial es de quienes están dentro del proyecto de ciudadanía blanco-mestiza, entonces incluso se presenta la imagen de los pueblos indígenas como el obstáculo para la modernización del país.

Ante ello, el EZLN enuncia la necesidad del recuerdo, la reivindicación del pasado indígena en la medida que éstos surgen como los auténticos luchadores, los verdaderos mexicanos, los originarios, quienes han forjado la historia como nación. Sin embargo, a las comunidades indígenas se les relegó al olvido, al desprecio y al sometimiento como pueblo mexicano, sin voz, sin rostro, sin patria y sin futuro. Y ese olvido colectivo, que el EZLN identifica con la expulsión de la historia, se ha llevado también la dignidad, para detenerla, petrificarla y hacerla pieza de museo.

Así, la falta de rumbo implica que no se es dueño de su destino colectivo; pero la certeza del pasado, la conciencia histórica como garante de la identidad étnica funciona como el cimiento más sólido sobre el que puede levantarse la respuesta sobre el ser, ya que en la memoria indígena está la fuente de la sabiduría, de los consejos y la guía para la acción. Entonces, la historia que da identidad, se convierte en historicidad, en presente que actualiza el pasado como continuidad en el ser, con la recuperación de los ancestros, integrando un recuerdo fundamental de constitución como pueblo, en el ritual que ha ligado por los tiempos a los hombres con las potencias de la sociedad y de la naturaleza.

Esa persistencia en hablar de los antepasados se presenta ligada a una cuestión central en el discurso zapatista: la lucha por la dignidad. "La dignidad ligada a la historia, a la recuperación de la memoria, a la 
necesaria batalla frente al olvido"; y a la vez la decisión por cambiar las miserables condiciones de vida (Rojo, 1996: 335).

Resulta así, que la recuperación del pasado vivido es determinante para contar con una identidad que fundamente las exigencias del presente y del futuro; y es esta recuperación la que hace posible restituir la dignidad de un pasado de lucha, de una tradición de autoafirmarse, epopeya que remite a la valentía, a la lucha como camino de futuro. Se trata de darle sentido a la vida, vinculando la lucha indígena con la lucha histórica del pueblo mexicano, a la vez que se legitima y reivindica el carácter nacional del movimiento, pero activando los significados que permiten la identificación de sí mismos como comunidad, las raíces de la identidad étnica. La historia es la base para reafirmar la identidad, autoafirmación que permite y exige el valor, lo que es el alimento de la insurrección armada.

Si la pregunta central de la identidad es ¿quiénes somos?, el reencuentro con el pasado habla de que se trata de "los hombres verdaderos", "los que en la noche andan", "los que son montaña". Y es que en esta autodefinición aparece la verdad, la voz de los antepasados que se transmite de generación en generación, y sólo aquellos que escuchen la palabra que viene de lejos serán dignos de ser llamados los hombres verdaderos. Por otra parte, las denominaciones señaladas, como "los sin rostro", "sin historia", remiten a la negatividad, a la ausencia de cualidades y al anonimato, precisamente a la negación de aquellos rasgos indispensables para la identidad colectiva (sin historia) y, aún más, al rechazo de la identidad individual, en la medida que no se tiene un rostro, una voz, una suerte. Claro está que esta demarcación implica darle cabida al otro, al enemigo, identificado a partir de una carencia que constituye, y que marca el aquí de nosotros y el de ellos, los extranjeros.

La existencia como hombres verdaderos “...hace referencia, por un lado, a la tradición (en la que camina la verdad) y, por otro, en la sinceridad (el empeño de ser fieles a las luchas y palabras de los antepasados), pero además a la originariedad, a la legítima posesión de las tierras (prometidas) de la que se ostentan como pobladores originarios y auténticos" (Rojo, 1996: 338).

El soporte material tierra se encuentra inmerso en la identidad, en un modelo de comunidad, vigente entre los pobladores y sucesores de tradiciones ancestrales, hace referencia a una ética de la subsistencia 
-de cara a una grave necesidad- cuyas bases centrales son el trabajo, el autogobierno y la defensa de las tierras; la garantía de esa subsistencia está en el eje de las principales características de la organización indígena y rural: elevada cohesión interna, respeto de las tradiciones como forma de vida, democracia participativa. Entonces, la identidad colectiva como ser indígena rural se encuentra indisolublemente ligada a la tierra, medio de producción y espacio para la vida de la comunidad.

Como oposición a la condición de hombres verdaderos, de palabra y lengua verdadera, actúa la mentira y la máscara del gobierno. Por eso se le contradefine como el enemigo (Rojo, 1996: 339).

Pero, cómo fue posible que "los más pequeños", "los sin rostro", hayan perdido el miedo y se lanzaran a tomar las armas contra el poder. Como elemento mítico-simbólico constitutivo de su identidad, el discurso del EZLN revela significativamente sus raíces en la imagen del topo, que al no dejar mirar la mirada que da miedo, como parte pequeña, sin voz ni rostro, en la marginación, es de ésta que toma su gran fuerza, que le da valor para luchar. No dejarse mirar por la mirada que domina les dio valor y seguridad en sí mismos.

El olvido, además de permitir evitar la mirada del enemigo que podría verlo débil y pequeño, hace posible que los así llamados "hombres verdaderos" se miren el corazón, y no sientan el miedo de mirarse en la mirada del que tiene el poder. De esta manera, la ceguera, el olvido y la marginación se convierten en aliados de los topos, reinventando y renombrando la vieja metáfora; pero cambiando los valores que expresa, puesto que el olvido no se agota en ser el castigo a que se somete al indígena, sino que es el arma que permite y lleva a la interiorización, el conocimiento de sí mismo que faculta, como consecuencia, sustraerse de la relación de poder en que estaría inserto, bajo vigilancia y control.

Ante esto, se alude a la identidad de la tradición indígena, como historia de lucha, de hombres guerreros, con vocación de sacrificio. El menzaje moral que el EZLN manda a la sociedad civil no únicamente se refiere a la búsqueda y recuperación de la dignidad, de la lucha frente a la injusticia, sino principalmente en la constatación de que, de nuevo, son los indígenas, los más pequeños, los que están dispuestos a sacrificarse por los demás. Las enseñanzas de su historia y su lealtad a la misma, hacen que estén dispuestos a sufrir para evitar que otros sufran, y a morir para que otros vivan (Rojo, 1996: 341). 
La idea de sacrificio se relaciona directamente con la muerte, como el mayor sacrificio que puede hacer el hombre. Pero la muerte puede y debe tener sentido, si se trata de una muerte digna, es decir, si tiene un lugar en la historia, ya que el recuerdo permite mantener viva la memoria de los muertos, los antecesores de ayer y de hoy a fin de que, por esa vía, los muertos no mueran del todo, para que produzcan vida.

La identidad, entonces, se enlaza estrechamente con la dignidad, de alguna forma se actualiza en las acciones y nos remite a la constitución del sujeto social que, como actor político, ha transformado su "mundo de vida", y ha encontrado una esperanza entre tanto olvido, la de convertir la dignidad y rebeldía en libertad y dignidad. Y es que la dignidad no sólo es lo único que les habría quedado, sino más bien la posibilidad real para que los hombres fueran nuevamente hombres, porque la dignidad se precipita y adquiere fuerza en la lucha. Por eso es que el paso de conversión al alzamiento se vincula necesariamente por el rechazo de aceptar pasivamente la humillación y la deshumanización, convirtiéndose en el núcleo duro de la movilización zapatista. Y lo más trascendente del planteamiento por la dignidad, radica en que esa bandera no es exclusiva o particular de los indígenas de Chiapas, sino que tiene validez en toda lucha de la existencia humana en una sociedad opresiva, y por ello es de alcance general.

La dignidad es una tensión que lejos de agotarse en su racionalidad, se proyecta más allá. Es una lucha contra su negación y por su realización. "Uno tiene dignidad o verdad, sólo luchando contra la indignidad o no-verdad actual. La dignidad implica un movimiento constante en contra de las barreras de lo existente, un subvertir y traspasar las acotaciones" (Holloway, 1997: 18).

Como grito de los no escuchados, la dignidad es la voz de los sin voz, es la verdad de la verdad negada; pero esa dignidad permite decir "aquí estamos", como movimiento contra la exclusión y por la inclusión, no sólo de los indígenas, sino de todos los no abarcados. Es el rompimiento simbólico y actual de las barreras, la afirmación de las unidades borradas por las clasificaciones y definiciones (Holloway, 1997: 19).

En otro nivel del análisis, la dignidad aparece como cuestionamiento de la separación entre la moral y la política, así como de lo privado y lo público. Se trata de un ataque contra la división de la ética y la política, que permite que los regímenes formalmente 
democráticos coexistan en todo el mundo con niveles cada vez mayores de pobreza y marginación social. O sea, es la voz del rechazo que todos sentimos ante el empobrecimiento y hambre masivos.

Así, en una forma sorprendente, el grupo de rebeldes zapatistas logró cristalizar y dar avance a los principales temas del pensamiento y la práctica de oposición que han sido motivo de discusión a nivel mundial en los últimos años: la cuestión del género, de la edad, de la niñez, de la muerte y los muertos, es decir, una visión y posición antipolítica de la dignidad que, al reconocer la opresión particular, concibe y apoya las luchas de las mujeres, los niños y los ancianos. La lucha por el ser que no acepta ya el desinterés.

Por lo mismo, la lucha por la dignidad se opone directamente al Estado como guardián y protagonista de la política que desconoce la dignidad. El movimiento zapatista es un movimiento antiestatal no solamente en cuanto a que desde luego encausó las armas en contra de él, sino en el sentido más profundo de que sus formas de organización y discurso son antiestatales.

El EZLN, en consecuencia con su identidad dentro de la nación, no se plantea una lucha por las comunidades indígenas solamente, el sentido de ésta estriba en una suerte de regeneración, de redención para todo el pueblo mexicano (Rojo, 1996: 341).

Asimismo, la forma en que el zapatismo ha construido su propia identidad generó una nueva relación entre lo particular y lo universal, por medio de la cual se impulsó que muchos otros movimientos particulares se identificaran con él en sus deseos de lograr un mundo de las diferencias donde los principios universales básicos sean el reconocimiento de las particularidades, a las voces e identidades que pueblan el mundo (Betancourt, 1998: 92-93).

Por ello, la cuestión esencial de los zapatistas es algo que es mundial y universal: el cómo combinar la "democracia con la identidad" (Kanoussi, 1998: 12).

En la base de la identidad del zapatismo, están los principios y la ideología que lo orientan y que, asimilados para lograr una voluntad y decisión indeclinables, se integran tanto de preceptos básicos, aplicados de manera tan flexible como intransigente, que tienen mucho que ver con la dignidad como valor supremo; y una ideología de cuestionamiento y enfrentamiento con el capital, y la posibilidad de 
construir una utopía colectiva, como opción de refundación nacional de una modernidad como "organización de las diferencias".

De ahí que los principios e ideología del EZLN estén directamente relacionados con la deconstrucción democrática de las armas y el poder; de la política como ética, y de la lucha resuelta por la autonomía como desafío para fundamentar el autogobierno, y como esfuerzo para enfrentar la miseria y marginación ancestrales, de los que el Estado no pretende hacerse responsable.

En conjunto, el registro de la identidad del EZLN manifiesta un profundo sentido simbólico del movimiento, en la medida que se reapropia tanto de valores, mitos y desmitificaciones de nuestra memoria colectiva de lucha por la independencia, la justicia y la democracia, como por el hecho de que corresponden a esa realidad a la que sólo nos acercamos a través de símbolos, diferencias e imaginarios sociales impuestos por el sistema a la sociedad civil, y que por ello es necesario que tengan otro significado para la lucha, en términos de claves que favorezcan la identificación. Asimismo, todo un conjunto de símbolos ancestrales, de fuerte arraigo en la vida de las comunidades indígenas, se ven unidos y expresando su retorno como principios junto a la simbología del sujeto que es capaz de constituirse por medio de la negación de su realidad opresiva.

Entonces, los símbolos culturales y sociales hacen posible el cambio de lugar de los indígenas alzados ante el conflicto, el asumir una identidad, una organización y las demandas, ya que se trata de cómo esas representaciones colectivas son el medio para "leer la realidad" e interpretarla. En los símbolos se conjunta la posibilidad de la palabra y de tener un nombre propio como sujetos, como si se acercaran al origen de los tiempos para otorgar el ser verdadero. Son consecuencia de la historia y por ella hablan, dicen algo que nos mueve en su busca, su función es decirnos una primera palabra para nuestra propia voz.

Una vez que hemos hablado de la organización y la identidad del zapatismo por separado, se requiere preguntar ¿Cómo se relacionan la organización y la identidad del movimiento zapatista para determinar su validez?.

Si aceptamos que las identidades no son meros datos o principios, sino la resultante de intercambios, decisiones e incluso oposiciones entre diversos actores sociales, entonces la identidad del zapatismo no 
sólo debe declararse sino actualizarse en una toma de acción consecuente con las interacciones conflictivas que lo definen socialmente. Y si se trata de tomar una posición en la historicidad desde el lugar de los excluidos, indígenas rurales dominados, sin voz ni rostro, ni sujetos de derechos como los otros que conforman la patria y la nación, esta no es posible hablarla, asumirla, argumentarla y defenderla si antes no se cuenta con una organización diferente, acorde con la situación que se quiere negar; pero sobre todo una ordenación y disposición de las fuerzas y conciencias individuales que en su integración y acción conjunta esté en posibilidades de armar un discurso del ser, es decir, identitario con base en una conversión del indígena en sujeto y actor social que interfiere en la historicidad de la nación para alzar su voz con la sociedad civil en la que busca identificación.

Asimismo, el zapatismo no estaría en condiciones de afirmarse y reclamar que su movimiento es una continuidad histórica en la lucha indígena y popular por alcanzar la democracia, justicia e igualdad por las que combatieron los revolucionarios de 1910-1917, sino se tratara de una organización armada, radical y valiente -y tal vez también utópica- capaz de enfrentar al poder político y reclamar un cambio social profundo y de nuevo tipo.

Igualmente, una organización que se alza en armas, declara la guerra al gobierno federal, y después convierte esa lucha en combate político llamando a la población a participar en sus propias trincheras, difícilmente lograría la vigencia de sus acciones si no estuviera fundamentada en una identidad flexible, en movimiento, con historia, que significa raíces e ideologías; pero que asimismo permite partir de una verdad. La verdad de los indígenas como premisa. Utilizando las armas para hacer escuchar su voz. Esta es la síntesis entre organización e identidad: la palabra que se articula en la lucha para recuperar su sentido. Hablada y nombrada por quienes se han negado así mismo como sujetos sin historia para la base de una organización disciplinada y jerárquica, así como democrática y comunitaria, puedan decir y constituir un discurso de la inconformidad del jya basta! que significa ruptura y decisión, la voz de los hombres verdaderos que reencuentran en el motivo guerrero la razón de cambiar el rumbo de los tiempos.

Organización e identidad conforman, entonces, una relación principal que actualiza la lucha y valida al sujeto que así se constituye, 
ya que una a otra se vinculan, puesto que es la afirmación en la práctica y la experiencia de una identidad indígena como organizadora de la comunidad y definidora de sus relaciones con los gobiernos federal y estatal. La identidad en positivo fue la respuesta a la exclusión de los indígenas, como tales, de la identidad y los derechos como ciudadanos mexicanos (Gilly, 1997: 68).

\section{Relación de legitimidad}

En este punto se trata de poder establecer la posibilidad de que los zapatistas, es decir, los indios, puedan realizar actividades relacionadas con la rebelión, tengan derecho a proponer cambios políticos al resto de la nación y a la autonomía. Se busca conocer la relación entre la organización del zapatismo y sus demandas (Uribe, 1998: 71).

Para poder determinar si el zapatismo es un movimiento que cuenta con legitimidad, si es verdadero, veamos cuáles han sido sus demandas principales, y qué relación tienen con la organización que han conformado, de tal forma que estemos en posibilidad de demostrar que efectivamente hay una relación de correspondencia, adecuación y vínculo entre la estructura orgánica y las exigencias del movimiento.

Según documentos básicos del EZLN, su movimiento enarbola tres demandas fundamentales: libertad, democracia y justicia; y que engloban un conjunto de importantes demandas particulares:

...una elección nacional democrática; renuncia del presidente de la República; reconocimiento del EZLN como fuerza beligerante; autonomía política, económica y cultural para municipios y comunidades indígenas; elecciones en Chiapas; revisión del TLC; anulación de la reforma al artículo 27; hospitales y médicos en los municipios; derecho a la información y una radiodifusora indigena dirigida por indigenas y manejada por indigenas, viviendas, luz, agua potable, caminos, drenaje, teléfonos, transporte; educación gratuita hasta la universidad; las lenguas de las etnias deben ser oficiales; respeto a la cultura y tradición indígenas y que la justicia sea adminitrada por los propios pueblos conforme a sus costumbres y tradiciones; trabajo, precio justo a los productos del campo y anulación de deudas; tiendas cooperativas; libertad de los presos políticos; retiro del ejército federal y de las policias; indemnización por los daños de los días de guerra; derogación del Código Penal del estado de Chiapas porque no nos deja organizarnos más que con las armas, porque toda la lucha legal y pacifica la castigan y reprimen; regreso a sus pueblos de los indígenas expulsados por los caciques; $y$ un punto especial con doce demandas especificas de las mujeres campesinas, entre las más importantes clínicas de parto, guarderías, alimento para los niños, cocinas y comedores colectivos, asesoría 
técnica para granjas familiares, talleres de artesanía, escuelas maternales y transportes (Citado por Gilly, 1997: 82-83).

Cabe resaltar la demanda fundamental por la autonomía indígena, que incluye los derechos, la cultura y la territorialidad (Díaz-Polanco, 1997: 167-184).

Se plantean demandas que tradicionalmente han erigido otras clases y sectores, como los obreros, el magisterio, el campesinado y el movimiento estudiantil; pero asimismo, expresan otras demandas no transmitidas por los sectores y agrupaciones políticas tradicionales. Retoman-además de las propias reivindicaciones indígenas- aquellas que provienen del ecologismo, el feminismo, los movimientos por vivienda popular, ONGs y otras, poniendo énfasis en su pluralidad y en una representatividad que se hace extensiva a la sociedad civil.

El zapatismo busca restituir lo político y la democracia desde una base ética, a la vez que las reivindicaciones de las particularidades sociales.

El reclamo por la democratización de la sociedad, adquiere hoy un sentido renovado y otro contenido: las demandas mínimas aparecen empalmadas, como parte de las demandas más radicales, así como transfiguradas y revestidas del carácter de estas últimas.

Plantear la democracia en las actuales condiciones, resulta algo tan cercano y próximo, a la vez que absurdamente distante, como esa utopía cuyo fin indicado por su proximidad, parece ser al mismo tiempo lo que determina el peligro de su disolución a manera de un espejismo (Machuca, 1998: 37).

En el centro de las reivindicaciones zapatistas está la cuestión democrática. El EZLN sostuvo que la democracia no podría existir con la muerte por enfermedad originada por la pobreza, con la desigualdad y la discriminación racial y que, el primer punto de la agenda de paz, sería el relativo a las cuestiones económicas, luego las sociales y por último las políticas.

Además, los zapatistas aseguraron que la lucha por la democracia es inseparable de la lucha por la justicia social. Una no puede caminar sin la otra. Ésta, que puede parecer una conclusión más o menos obvia, estaba en la práctica cancelada en el discurso liberal, conservador e incluso de sectores de la autodenominada izquierda democrática (Tiguera, 1995: 55-56).

Esto último es muy importante, ya que cuando se lucha por democracia con justicia social, la lucha adquiere un carácter 
anticapitalista. Significa que la lucha por la democracia y por el socialismo ganan una dimensión cotidiana real y una dimensión que el liberalismo no se atreve a resolver, para el que no tiene palabras (Tiguera, 1995: 57).

Pero lo importante es que ya el EZLN dio un paso en firme al poner en evidencia lo que era un hecho conocido: demandas por necesidades básicas no cumplidas, en tanto que se aparentaba lo contrario. Por ello, el EZLN lanza dos conjuntos de demandas dirigidas unas al gobierno federal, y otras a la sociedad civil:

Al gobierno, sobre los problemas regionales de los pueblos indios, con las demandas democráticas nacionales. Asimismo, de incorporación de derechos culturales comunitarios en un marco de vigencia de derechos ciudadanos que tendría que ser modificado y redimensionado en el sentido de ajustarse a la inclusión de un sujeto colectivo de derecho.

A la propia sociedad civil, la demanda va en el sentido que ésta puede dar de sí, más que pretender su educación revolucionaria; o acicatear a la lucha de una clase contra otra.

Son demandas para saturar la modernidad, para fundar una nueva dimensión histórica capaz de satisfacer las necesidades que la modernidad ha generado y que no ha podido satisfacer bajo el actual sistema económico-social (Betancourt, 1998: 84).

Los zapatistas de finales de siglo reivindicaron el contenido profundo del viejo movimiento revolucionario y su lucha por el establecimiento de una nueva relación entre gobernantes y gobernados, el ejercicio de una intensa vida comunitaria, el reconocimiento de las tradiciones indígenas, la reunificación de demandas económicas, políticas y culturales, en suma, su lucha por una nueva forma de poder que devolviera a los individuos y a las comunidades, el ejercicio directo y el control social del poder político (Betancourt, 1998: 83).

El siguiente paso fue la reivindicación de un pueblo en armas.

La importancia fundamental de las demandas del movimiento radica en que cumple, al menos, las siguientes funciones básicas en su proceso.

a. Por medio de las demandas se establece formalmente el vínculo del movimiento con el conflicto social dentro del que toma una 
acción particular. El conflicto, en la medida que demilita y abre un campo de posibilidades de comportamiento colectivo, es el que otorga sentido a las acciones, no determinándolas sino marcando las condiciones sociales estructurales que manifiestan una tensión significativa en el sistema social. Por ello, el campo de conflictos es el escenario dentro del que el sujeto social actúa, se historiza y asume una toma de posición en torno al conflicto. Es, asimismo, el encuadre dentro del que el EZLN presenta las demandas del movimiento, reclamos que en principio expresan las necesidades básicas de la población indígena levantada en armas, así como de la sociedad civil del país.

Ahora bien, las demandas del EZLN, unas ya planteadas por otros movimientos y sujetos sociales, y otras nuevas y generales no tienen el mismo significado si son exigidas con las armas en la mano por una organización que se autonombra ejército del pueblo, es decir, adquieren ahora un significado profundo, verdadero, en tanto es la verdad de las comunidades indígenas en combate la que se presenta como una palabra diferente, armada "de verdad y fuego", como demandas del movimiento que está en lucha, y a la vez con esas mismas se establece el contacto directo y el vínculo con el conflicto, iniciándose así un episodio en torno a la evidencia y exigencia de las demandas.

Entonces, la comunicación y expresión de las demandas es condición y momento inicial formal del proceso de constitución del sujeto social, del actor colectivo que así establece los ejes sobre los que se desarrollará el proceso del movimiento social. Con las demandas, el sujeto toma posición, abre el campo conflictivo; pero lo fundamental es que como movimiento social ya habló, ya declaró las palabras que había que decir, porque forman parte del discurso, tanto de los indígenas como de la sociedad civil toda, en determinada escena en la que se trastocaron los tiempos, se alteró el orden y se tuvo que gritar fuertemente para que las demandas se escucharan con claridad, con la voz de los hombres de la selva y de la lucha. Demandas que desde las necesidades que las alimentan también hablan de las aspiraciones y deseos, de la intención de ser digno ante la muerte, y sobre todo de defender la vida de la humanidad. 
b. Como ya se ha dicho antes, las demandas expresan las necesidades básicas de la población. En tal sentido, atendiendo a los documentos y declaraciones del EZLN, sus demandas, además de incorporar un conjunto de reivindicaciones elementales, expresan cambios y transformaciones de fondo, como la renuncia del entonces presidente espurio de la República mexicana, o la modificación del Código Penal del estado de Chiapas, que desde luego significan una gran dificultad e incluso imposibilidad real de consumación; pero que en cambio traen al debate público cuestiones trascendentales en las que la sociedad civil debe intervenir para cambiar la vida política y social en México. Es decir, que en tanto se exponen como demandas con las que se inicia formalmente un episodio actualizado del conflicto indígena y político nacional, descubre e inicia una corriente de información, de comunicación, opinión y actitudes hacia ese tema específico, ya que por asociaciones "libres" se generan los lazos temáticos y con problemas que nos aquejan e importan. Por ello es que expresan necesidades sentidas, puesto que un mal comportamiento presidencial puede afectar a grandes sectores de la población, máxime si como en México, la desigualdad y polarización social se han agudizado con el neoliberalismo.

Asimismo, con la declaración de las demandas, se presentan banderas de lucha a seguir por diferentes sujetos sociales de la sociedad civil, lo que representa ir hablando en público acerca de los problemas que nos importa resolver y que asimismo son de igual interés para otros sujetos. La demanda habla por el sujeto y éste se afirma en las demandas. Como comienzo formal de un discurso, en el marco del conflicto social, que no puede ser el discurso de las armas, las demandas encuentran las palabras que han atravezado por los siglos y los tiempos a los indígenas, y también a la sociedad civil. Al hablar de sus y nuestros problemas, así como los de muchos de otras naciones y ambientes, con las demandas se manifiesta la disposición de intervenir en su análisis y solución. De eso se trata precisamente, de que en la declaración de la demanda se afirma implícitamente la determinación de participar de manera importante para solucionar la situación, causada por el conflicto. 
c. La traducción de las necesidades en reclamos constituye otra de las funciones primordiales de las demandas, ya que al decir su verdad, el movimiento al irse constituyendo en sujeto social con participación, parte de una posición en el conflicto en la cual el poder le ha impedido saber, conocer acerca de esas demandas, de las necesidades de las cuales ellos no saben, para ir pasando a través del proceso del movimiento a una posición en la que, ahora, el sujeto es el que sabe de su demanda, en tanto que va interviniendo y modificando su relación con la parte que representa al conflicto. Así, las demandas inician el proceso que lleva al sujeto de un no saber porque el poder ha sido quien se ostenta como el supuesto saber, a un saber que tiene la verdad como premisa, y que únicamente puede surgir cuando se ha logrado acceder a la posición del saber que le correspondía.

Al presentar la necesidad como reclamo, las demandas exigen al movimiento una decisión de principio para seguir un camino impensado y desconocido que implica una reflexión profunda del sujeto, una elevación de su valor al nivel de discurso que requiere escribirse; verdad que impulsa al cambio, a la realización del sujeto como tal.

d. Como eje problemático de un proceso de análisis dentro de un conflicto social, las demandas actualizan los fundamentos éticos de la organización social, por lo que llaman al imaginario social de los niveles de vida elementales de la población, sus derechos políticos y aspiraciones personales, estableciendo un enlace conflictivo entre lo que debiera ser y lo que existe; y que en la memoria colectiva tiene un peso importante que permanece latente y aparece en cualquier momento como significante de las preocupaciones generalizadas de la sociedad.

Asimismo, como eje analítico que posibilita el encuentro de posiciones opuestas en un nivel de radicalidad diferente, las demandas marcan los derroteros por los que habrá de cruzar el movimiento, puesto que el constante decir de las demandas, su llamado a la verdad y a una acción consecuente, va llevando hacia puntos límite en que el EZLN y el gobierno federal tienen que ofrecer respuestas y asumir posiciones. 
Llegados a este punto hay que responder a la pregunta de si el EZLN tiene legitimidad, cuando analizamos la relación entre su organización y las demandas que enarbola. De si el zapatismo puede clamar auténticamente por el cumplimiento de ese conjunto de exigencias.

Desde el punto de vista estrictamente lógico, puede afirmarse que el EZLN cuenta con legitimidad, tanto porque cualquier grupo social en principio tendría el derecho de reclamar por la solución de problemas sociales, como por el hecho de que el sujeto social muestra y demuestra que su verdad es la causa del movimiento, y que por tanto el reclamo es plenamente justificado, por lo que corresponde a ellos hacerlo de la forma y con los medios que las propias condiciones del conflicto así lo determinen. Es decir, que si las demandas del EZLN se expresaron junto con la violencia de las armas, es porque en el campo de conflictos donde surge la toma de acción del movimiento, las armas se han empleado para evitar que se resuelvan las necesidades. Esto, además de mostrar la pertinencia del levantamiento zapatista, se enlaza con la historia de levanta- mientos por la libertad, la justicia y la democracia.

Así, la organización político-militar de las poblaciones indígenas con sus formas de participación democrática participativa y de convivencia comunitaria, se declara legítimamente dispuesta a luchar por las demandas principales del movimiento, asumiendo la responsabilidad de defenderlas; de hacer causa de ellas y desfilar con la misma intención por los caminos que puedan llevar a su consecución. Una vez establecidas las demandas, el movimiento tendrá que girar a su alrededor, y avanzar en el proceso de su devenir impredecible.

En buena medida, la legitimidad del movimiento zapatista quedó evidenciada cuando el Estado, en lugar de aplastarlo negocia con él y toma acuerdos; aunque finalmente no los cumpla, como en el caso de los acuerdos de San Andrés.

\section{Relación de eficiencia}

Interesa analizar cuál es la conexión entre la organización del EZLN y el desempeño que ha tenido hasta el momento. Para llevar a cabo este ejercicio, es necesario contar con un cuadro representativo de las principales acciones del movimiento zapatista, y poder ponderar con ello la capacidad que ha exhibido en cuanto a los resultados logrados.

Dada la complejidad para hacer un recuento aceptable del desempeño del EZLN, se irán considerando los siguientes aspectos 
relacionados con su actuación: a) los objetivos fijados; b) las tareas emprendidas; c) las acciones realizadas; d) las estrategias políticas seguidas; e) las principales movilizaciones llevadas a cabo y f) la formación de redes de solidaridad; g)La trascendencia del EZLN se analizará tomando en cuenta propiamente la influencia alcanzada, la resonancia del movimiento, la generación de coaliciones de descontento, las formas de comunicación y la fuerza de convocatoria.

a) En cuanto a los objetivos principales del movimiento, aparece ante todo el de construir una nueva relación política a partir de varias fuentes y no sólo del zapatismo, en otra relación con la ética, una política de izquierda que no fuera la "imagen invertida" de la política tradicional. En una palabra, la edificación de un contrapeso de oposición frente al poder. Los dos objetivos centrales del EZLN son: luchar por las demandas de las poblaciones que conforman su base de apoyo; y construir su propio espacio político como movimiento social (Kanoussi, 1998: 12).Asimismo, el movimiento precisó objetivos particulares y específicos para todas las acciones importantes de la lucha, con base en un objetivo particular fundamental para la sociedad civil, y que es el avance en la transición a la democracia, así como impulsar la generación de espacios en los que cualquier ciudadano participe en la discusión de los grandes problemas nacionales y proponga soluciones.

b) En cuanto a las tareas que realiza el EZLN, más que intentar aquí un inventario exhaustivo de ellas, analizaremos algunos de los quehaceres que los ocupan, en relación estrecha con su organización y las demandas que ha formulado. En términos generales, las tareas pueden clasificarse en dos grandes apartados: las de la lucha y las de comunicación. En el primer caso, está todo el conjunto de faenas que realizan los integrantes del movimiento zapatista vinculadas con el orden militar, es decir, jerarquizadas y establecidas por los mandos militares y acatadas tanto por los soldados de la tropa como por las comunidades de apoyo en la selva y la montaña de Chiapas. Por ello, las tareas militares son miles y todas ellas llevadas a cabo con precisión, exactitud y control. Asimismo, dentro de las tareas militares se encuentran las actividades eminentemente políticas y propagandísticas del movimiento, todas ellas 
subordinadas a las grandes tareas de la lucha.Por su parte, las tareas de comunicación constituyen una originalidad e iniciativa muy avanzada, ya que a diferencia de los movimientos revolucionarios anteriores en México, el EZLN estableció desde el primer momento del alzamiento una comunicación abierta, fluida, directa, y sobre todo dirigida a la sociedad civil, con una clara expresión de las demandas, y creando canales de comuinicación que además de llegar a despertar la conciencia de la sociedad, llamaban a ésta a participar activamente con el zapatismo, y en la transformación de su realidad inmediata bajo nuevos principios, aunque con similares banderas de lucha.

c) En estrecha relación con las tareas, el EZLN ha desarrollado y continúa sorprendiendo al mundo con sus atrevimientos, actualización de las intervenciones, e intransigencia con las demandas fundamentales. Dentro del cúmulo de acciones realizadas, destacan algunas acciones político-militares, y de organización de lucha internacional contra el neoliberalismo, que nos permiten analizar el alcance del movimiento y reflexionar acerca de su actuación en lo esencial.

d) La primera gran acción militar fue la toma de las cabeceras municipales de San Cristobal de las Casas, Ocosingo, Altamirano, Las Margaritas y Chanal en el primer día de 1994, por fuerzas del EZLN, por cierto acompañada de medios de comunicación. Fue de esta manera como la rebelión zapatista se convirtió, de pronto y sin ser su propósito, en una rebelión "...mucho menos sangrienta que otras en América Latina", ganando de inmediato simpatías más que temores, así como una difusión inusitada con muchas imágenes de los alzados (Rodríguez, 1997, 371).En los primeros días del levantamiento, los rebeldes suscitaron un creciente movimiento de apoyo y protección contra la ofensiva del ejército federal. Ningún partido político encabezó ese apoyo: en principio fueron grupos y organizaciones de la sociedad civil. Y más que desencadenar una guerra popular y derribar al gobierno de Carlos Salinas, al poco tiempo ambas partes abrieron negociaciones forzadas por las movilizaciones, por el año electoral, por la actual crisis del poder nacional, caracterizada por las divisiones internas, y también por la imposibilidad de terminar con la rebelión con una ofensiva 
militar que daría por consecuencia cientos de poblados arrasados y un grupo inalcanzable de guerrilleros que habrían podido permanecer luchando durante años operando en los refugios al interior de la selva lacandona (Gilly, 1997; 84).

Estas manifestaciones sociales en contra de la guerra y por una paz justa y digna en Chiapas no sólo obligaron a reflexionar al gobierno federal acerca de cómo debería conducirse, sino que a la vez permitieron que el EZLN descubriera a un actor que, por su propia pasividad, parecía dormido desde hacía tiempo: la sociedad civil. Este reconocimiento de parte de la sociedad civil, principalmente por parte del EZLN, habría de ser muy importante en el futuro del levantamiento y una garantía de seguridad para sus delegados en las siguientes fases de esta epopeya chiapaneca (Rodríguez, 1997: 372).

La segunda gran acción importante, con Samuel Ruiz, obispo de la diócesis de San Cristóbal, como mediador, fue el diálogo por la paz y la reconciliación entre la representación del gobierno federal y los representantes del EZLN en la catedral de San Cristóbal.

La primera etapa del diálogo, terminada el 2 de marzo de 1994, concluía con dos propuestas divergentes, la del EZLN y la del gobierno a través del comisionado. El EZLN condujo a consulta la propuesta gubernamental. El no del EZLN a la propuesta de un gobierno que finalizaba su mandato se acompañaba de la Segunda Declaración de la Selva Lacandona, con una convocatoria a la sociedad civil y a personalidades del mundo político e intelectual a asitir a Chiapas para constituir en el ejido de Guadalupe Tepeyac la Convención Nacional Democrática.

Y si bien las diferencias a su interior habrían de terminar por hacer fracasar a la convención, interesa resaltar aquí el alcance y perspectiva de esa acción política y comunicativa, puesto que el EZLN llamaba a la sociedad civil, plural y diferenciada, a organizarse para presionar al poder a fin de que atendiera las demandas más sentidas y elementales de la población mayoritaria del país y, sobre esa base, ir construyendo un México en el que lo único que impere sean la democracia, la libertad y la justicia.

Después de no lograr tampoco éxito con la conformación del movimiento de liberación nacional (MLN), y de resultar atacado el zapatismo con el intento de detener a Marcos y otros altos dirigentes del EZLN en una acción fugaz del presidente Zedillo; y debido a las nuevas manifestaciones sociales bajo la consigna de "todos somos 
Marcos", se promovió y aprobó la llamada Ley del Diálogo, y la creación de la Cocopa.

Hay que tener en cuenta, para valorar adecuadamente las acciones del EZLN, que durante el diálogo, el cerco militar, la destrucción de poblados y la expulsión de campesinos de sus casas y pueblos no dejó de registrarse. La guerra de contrainsurgencia (o también conocida como "guerra de baja intensidad") continuaba sistemáticamente.

Como resultado de las consultas y debido al momento tan importante en que se transitaba para definir los derechos y la cultura indígenas, el EZLN divulgó su Cuarta Declaración de la Selva Lacandona tres días antes de que fuera inaugurado el primer Foro Nacional Indígena en San Cristobal. En dicha declaración se convocaba a la formación del Frente Zapatista de Liberación Nacional, como una organización verdaderamente democrática, independiente de las organizaciones políticas formales, y que no aspiraran al poder (Rodríguez, 1997: 380).

Meses más tarde, el EZLN lanzó otra interesante y novedosa propuesta: que todos los pueblos del mundo que estuvieran en contra del neoliberalismo y por la humanidad, deberían dialogar entre sí y buscar una organización de alcance internacional para impulsar acciones en esos dos temas. Al efecto, se llevaron a cabo dos encuentros continentales: el americano y el europeo. El intercontinental resultó exitoso, ya que concurrieron más de mil ochocientas personas de 43 países y cerca de mil seiscientos mexicanos, además de los anfitriones indígenas en los cinco Aguascalientes que se acondicionaron para los eventos (Rodríguez, 1997: 380).

Cabe recordar que de la mesa 1 del diálogo emanaron los acuerdos del 16 de febrero de 1996 sobre los derechos indígenas y el compromiso de que esos acuerdos serían traducidos en iniciativas de reformas constitucionales que se presentarían al Congreso para su discusión y, en su caso, aprobación. También recordamos que un año después tales acuerdos serían desconocidos por el gobierno federal al no aceptar la propuesta de la Cocopa, misma que corresponde adecuadamente a los acuerdos originales. Como sabemos, a la fecha el diálogo se encuentra suspendido, en un periodo de estancamiento que no se sabe cuándo cambiará. Entre las últimas acciones importantes del EZLN, está la Quinta Declaración de la Selva Lacandona, agosto de 
1998, donde el zapatismo reivindica su resistencia, la resistencia del silencio, contra la guerra, e insistiendo en la necesidad del cumplimiento de los acuerdos de San Andrés, retomando las posibilidades del diálogo y la negociación a condición de que sean verdaderos, en la que desde su punto de vista es "la hora de los pueblos indios, de la sociedad civil y del Congreso de la Unión". En tal sentido, se hace un llamamiento a la sociedad civil, al poder legislativo y al mismo gobierno, para avalar la propuesta de la Cocopa en torno a la ley de derechos y cultura indígenas, a través de una consulta nacional; pero, lo que parece más importante aún, que se trata de una acción de reorientación para alcanzar la paz y defender las demandas fundamentales del movimiento zapatista.

d) Como parte esencial de su desempeño, el EZLN ha desplegado un conjunto de estrategias políticas insólitas y novedosas: ante todo fue capaz de convertir en político y movilización civil lo militar, "pero además ha socializado tácticamente lo militar, camuflajeando al mismo tiempo a sus contendientes como parte de la propia dinámica de posiciones y metamorfosis de las maniobras" (Machuca, 1998: 47).Como estrategia política, el EZLN ha logrado transitar de la insurrección táctica inicial a la lucha política, como una posibilidad para que la sociedad civil se organice como una oposición diferente a lo conocido. En ese empeño, diversos sectores de la sociedad civil impulsan para favorecer los medios que permitan al EZLN estar en capacidad de desplegarse como una fuerza política legalmente reconocida (Machuca, 1998: 45). Sin embargo, en lo relativo a las estrategias político-militares del EZLN, está claro que no actuó como una guerrilla, sino como un ejército en forma, que no practica el asedio y guerra de desgaste, sino una toma de posiciones y ataque frontal, asumiendo la ofensiva en cuanto es posible. Sin embargo, en términos realistas la desventa- ja material de los zapatistas era evidente, por lo que inmediatamente se hacen llamados urgentes a la sociedad civil por parte del EZLN para organizarse y asumir un papel protagónico en la solución del conflicto.

Si no existía confusión entre la acepción táctica y el objetivo de consolidación de una organización político territorial, nos encontramos con una versión original y muy dinámica de combinación de guerra de posiciones con la guerra de maniobras en el terreno 
político militar y social de las comunidades; por ejemplo entre espacios regionales ganados y maniobras de acción sorpresiva; además del avance y el repliegue articulado entre el sector armado y sectores civiles de la población (Machuca, 1998:41).

Por su parte, la autonomía perfilaba una forma de oponerse a nivel regional, en principio como expresión de desobediencia civil organizada, para demostrar que el país puede y empieza a dar pasos en el sentido de gobernarse progresivamente de manera diferente; por lo que es posible que esa forma de defender las autonomías, como un poder paralelo, por lo mismo contradictorio, pudiera ser considerado como un aspecto de la guerra de posiciones.

Un ejemplo ilustrativo de la importancia de la política de la guerra de emplazamientos, es que una acción para evitar arriesgar la suerte del EZLN en el terreno militar, fue la de ganar posiciones en el terreno estratégico de las negociaciones y la ampliación de los consensos a nivel de la sociedad civil, convirtiendo así el difícil triunfo militar del zapatismo en una conquista política así como el reconocimiento a nivel nacional e internacional.

Asimismo, el espacio de las negociaciones se presenta como doble filo que podría ser el principio de los esfuerzos para lograr un nuevo pacto social; pero a la vez la etapa más compleja de superar, de ahí que represente un momento crucial para alcanzar puntos de solución efectivos.

El EZLN se ha desarrollado en contrapartida y en referencia con distintos movimientos: municipal, campesino y autonomista, lo que indica un aspecto de su capacidad técnica para abarcar al cuerpo social que representa e impulsa a luchar; a la vez que puede transitar de lo militar a lo político.

La flexibilidad de estrategias y técnicas particulares, muestran que los objetivos no cambian, y que en la guerra como en la política, el EZLN cuenta con planteamientos para cursar el movimiento por diversas vías, con acciones adecuadas a cada situación concreta, privilegiando en todo momento los objetivos estratégicos, y dejando que éstos sean los que orienten las técticas pertinentes en una actitud de escucha que le ha permitido ir pulsando a la sociedad, incidiendo en sus síntomas, orientado todo por las necesidades de la lucha. 
e) Las movilizaciones del EZLN constituyen otro factor primordial del desempeño, ya que se trata de acciones de autoafirmación, ocupación de los espacios, demostración de fuerza y organización, y de conjunción de medios y fines en una racionalidad que, además, ejerce un efecto demostrativo en el conjunto de la sociedad, y a la vez actualiza y personifica el conflicto que le ha dado origen al movimiento. Las movilizaciones son las formas elementales de la organización, surgidas de las necesidades y vivencias, de lo cotidiano y su relación con la concepción general del mundo y de la utopía. Se trata del movimiento social donde no hay vanguardias sino acciones, comunitarismo y asociativismo, tampoco partido sino movimiento, ya no se trata de la organización formal, sino de la forma que adopta en función de las movilizaciones que es capaz de desarrollar. Por ello, las grandes movilizaciones que generó, organizó y dirigió el EZLN son parte de la lucha y expresan una ideología combativa y resuelta, con una radicalidad que exige mucho esfuerzo y despliegue de iniciativas. Desde el levantamiento armado el 1 de enero de 1994, y hasta la fecha, las movilizaciones del EZLN marcan momentos y episodios sobresalientes del conflicto, que aunadas a las movilizaciones del Frente Zapatista de Liberación Nacional, como expresión política del antipoder (Santillana, 1996:6-20), y el conjunto de movilizaciones promovidas por el zapatismo configuran un cuadro caracterizado por el nuevo impulso a las movilizaciones en todo el país, que expresan y refuerzan activaciones de luchas y pasos de la sociedad civil hacia un mayor protagonismo y presencia pública.

f) El otro aspecto relevante del desempeño que es necesario considerar se refiere a la capacidad del EZLN de establecer redes de solidaridad, como una acción muy compleja, que requiere además de un alto nivel de organización, también un sistema de trabajo político de gran experiencia y solvencia, donde la generación de redes de apoyo, seguimiento, mantenimiento y multiplicación de los "cuadros" adquiere un valor especial, sobre todo porque el gran impulso del EZLN deriva ahora en la conformación de un gran movimiento social que sería el zapatismo -o neozapatismo-, y cuyos rasgos de identificación 
con el movimiento se dan en las acciones mismas de la lucha, y les confieren una dimensión diferente como movimientos, con la concepción de un mundo democrático donde la representatividad se rija por el principio de mandar obedeciendo y las funciones no se constituyan en herramientas del poder por parte de la resignificación de los valores sociales y constituye la creación de una nueva utopía (Ceceña, 1998: 147). Se trata de reafirmar por qué un movimiento de esta naturaleza tiene que sustentarse en la democracia, base sobre la cual puede sobrevivir frente a este capitalismo fragmentador y atomizador que hace del mercado el único validador social. Así, la democracia participativa, deconstructora del autoritarismo y de las relaciones de poder, es la única posibilidad de establecer un comunitarismo universal capaz de derrotar al capitalismo neoliberal en el único espacio que no puede conquistar a través de la legalidad del mercado que constituye el espacio del sujeto colectivo y, por lo mismo, la negación del individuo objetivado (Ceceña, 1998: 147).

En cuanto a la trascendencia del movimiento, ésta resultó muy significativa, ya que “...el zapatismo es un adelanto que nos muestra ese reclamo ciudadano que se ha considerado tan avanzado y tan exclusivo del ambiente político urbano. En esa vía, el movimiento zapatista traspasa y trasciende sus limitaciones propias, para mostrar lo que la nueva condición de ciudadanía puede aportar potencialmente, como un recurso de transformación de nuestra condición de vida" (Machuca, 1998: 39).

El EZLN ha logrado un alcance nacional e internacional: se mueve en un terreno regional, en tanto que articula y sincroniza su posición y demandas acerca de los problemas regionales de los pueblos indios con las democráticas nacionales, como ya se indicó más arriba; planteando que la solución democrática del país pasa por resolver la cuestión indígena, pero que la solución definitiva a este conflicto requiere la lucha contra el neoliberalismo, es decir, la transición a la democracia y la refundación nacional como su objetivo esencial (Machuca, 1998: 47).La trascendencia del zapatismo estriba en que de la disputa de la rebelión indígena con el Estado nacional que se inició con la ocupac ción del espacio físico, terminó creciendo en una contienda de múltiples espacios: políticos, simbólicos, discursivos, dentro y fuera 
del territorio mexicano. Además, la rebelión del EZLN ha promovido en México un movimiento indígena independiente del gobierno, constituido formalmente en octubre de 1996 en el Congreso Nacional Indígena. E igualmente ocasionó un importante debate nacional acerca del problema indígena, especialmente sobre cultura, derechos y autonomía, contribuyendo así a la diversificación y democratización de la cultura política mexicana (Gilly, 1997: 89). También trascendente es el debate que inaugura el EZLN por el discurso, dentro del discurso y por medio de él. En su lenguaje combinado de imágenes modernas y símbolos ancestrales, el zapatismo no plantea un retorno al pasado remoto o reciente: más bien apunta a la posibilidad de una modernidad compartida, que no atente contra esa historia-identidad y sus portadores, sino que los incluya en una realidad con igualdad ciudadana.

La clave de la resonancia mundial de la lucha zapatista radica en que es una lucha que tiene el desbordamiento como principio central. "Una lucha que fuera solamente por la autonomía indígena o por la soberanía nacional no tendría la misma resonancia. Desde el principio la lucha de los 'sin voz, sin rostro' ha sido una lucha no por la identidad, no por la definición sino contra la identificación, contra la definición, contra la clasificación" (Holloway, 1996: 47).

Lo que se escucha en la resonancia del zapatismo es la vibración de la insubordinación contra y dentro del capital. "El zapatismo como lucha de desbordamiento, lucha que va más allá de cualquier definición, la institucionalización de la lucha, su limitación a la política chiapaneca o mexicana. Y es que el movimiento zapatista, como cualquier otra lucha, es un movimiento contradictorio, un conflicto constante entre definición y desbordamiento. El capitalismo, o neoliberalismo, es la definición. Nosotros, como humanidad, somos el desbordamiento" (Holloway, 1996: 53-54).

La capacidad del EZLN para expandirse es potencialmente reducida si tenemos en cuenta a la rebelión como "indígena" o "campesina". Lo importante, no obstante, es advertir las características de una organización que puede cuestionar las estructuras del poder a nivel nacional, y tener influencia significativa en amplios sectores urbanos. Asimismo, aunque su composición social sea limitada (indígena), que espacialmente se encuentran restringidos como fuerza político-militar, y sus objetivos y demandas representan 
reivindicaciones sociales, económicas y políticas principalmente para las comunidades indígenas, su programa nacional ha tenido importante resonancia en las luchas y debates de los grandes problemas nacionales (Tiguera, 1995: 45).

Uno de los aspectos más importantes de la trascendencia que ha alcanzado el zapatismo tiene que ver con el hecho de que impulsó como pocos movimientos las coaliciones de descontentos, caracterizadas por la capacidad de dar expresión a motivos generalizados de descontento social, y articular con ella la crítica radical del régimen que causa el descontento; que son abiertas e incluyentes, lo que favorece que confluyan en ellas todas las ideologías y clases sociales; que cuentan con estructuras organizativas flexibles, sin dirección política centralizada, que utilizan para concertar su acción más que para administrar las reivindicaciones, aunque pueden contar con un núcleo activador disciplinado y coherente, sujeto a estructuras organizativas menos rígidas, se autolimitan a sus luchas parcialese en campañas temáticas, apartándose abiertamente de ideologías abstractas y totalizadoras, emplean por lo general medios democráticos y procedimientos legales, que incluyen los de la resistencioa civil, así como emblemas articuladores de la acción colectiva, que pueden tomar la forma de manifiestos (Esteva, 1994: 48-49).

Por un lado, el zapatismo impulsó el descontento profuso, ya que trajo a la palestra una acitud latente en millones de mexicanos. "Lo que muchos pensaban y sentían, pero no se atrevían a expresar abiertamente o no sabían cómo traducir en un gesto efectivo, encontró articulación inmediata y eficaz en una sola palabra" (Esteva, 1994: 51-52).

Pero, a la vez, acentuó el descontento confuso, ya que el zapatismo influyó sobre otras formas de descontento ampliamente generalizadas, mas no las encauzó con la misma precisión que la de rechazo al estado de cosas, ya que el carácter de sus principales demandas no lo permitía. Así, al proclamar libertad, justicia, democracia, el zapatismo enarbolaba banderas ya utilizadas en muchos movimientos y durante mucho tiempo; pero buena parte del descontento que el EZLN contribuyó a emerger, con una nueva fuerza a esos lemas, apareció contaminado ya de confusión, la que no ha sido fácil resolver, volviéndose además difícil de manejar y de asimilar en las nuevas condiciones. 
Lo importante, sin embargo, es que como generador de coaliciones de descontentos, detonó y abrió camino para la expresión de múltiples disgustos, sobre la base de su radicalidad y su palabra, donde el EZLN funciona como un núcleo activador de amplios discensos que se formaron o pusieron en acción a raíz de sus iniciativas, y podrían constituir la fuerza social capaz de dar un carácter revolucionario a los procesos en curso, al conducirlos hacia una asamblea constituyente que redefina el marco jurídico y constitucional de la nación.

"El impacto del EZLN puede atribuirse, en buena medida, a su capacidad de activar a otros, en la llamada sociedad civil, y a su ma-rez política, al resistir la tentación de conducirlos" (Esteva, 1994: 45).

También en lo relativo a su trascendencia, resultó fundamental la comunicación que estableció el EZLN, sobre todo con la sociedad civil, ya que la comunicación de los rebeldes se ha vuelto fluida por la existencia previa de una prensa democrática independiente, y también por la novedad del lenguaje y de los símbolos que utiliza en sus comunicados. Tal manejo sumamente moderno de la comunicación, tanto en el contenido como en sus medios de expresión, tomó por sorpresa al gobierno federal y logran un diálogo en el que se consensan las posiciones y demandas. Sin embargo, a pesar de esa importante comunicación con la sociedad civil, es claro que ésta tiene una organización política muy incipiente para enfrentarse y derrotar en forma organizada al régimen en México.

La posición del EZLN se definió desde los primeros comunicados, $\mathrm{y}$ los mismos planteamientos han sido reiterados desde aquél momento: la línea editorial zapatista responde a la consigna "ahora o quizá jamás" (Nolasco, 1997: 49).

Asimismo, un ingrediente especial en la acción comunicativa del EZLN, es el estilo propio del movimiento, que se desempeña a través de paradojas, en ocasiones lúdico y antisolemne en un uso que provoca rupturas discursivas, políticas y simbólicas, incluso de concepción sobre el poder, buscando un reencuentro entre la ética y la política.

La comunicación adquiere una función trascendente, donde sobresale un concepto renovado de ciudadanía y de democracia en su acepción más amplia y característica de una sociedad compleja. Pero lo más impactante ha sido que el zapatismo se mostró como una nueva fuerza discursiva capaz de recuperar la tradición oral, los correos humanos y la literatura epistolar, de la misma forma en que se utiliza un 
sofisticado manejo de los medios de comunicación actuales, desde la prensa hasta el Internet. Complementariamente, demostró su talento y visión para elaborar un discurso universalista, dentro del que convivían y coexistían en igualdad de condiciones, las lenguas indígenas, el español y los idiomas internacionales (Betancourt, 1998: 87).

Y tal vez, de la mano con la relevancia implícita del acto comunicativo, está su capacidad para convencer, lo que ha generado una importante corriente internacional en favor de la transición a la democracia en México.

En estrecha relación con el despliegue comunicativo, está la fuerza de convocatoria del EZLN, que con un poder inusitado logró convocar a sectores a los que nunca había llegado la izquierda en el país. Esa capacidad para atraer las diversas muestras de solidaridad resultó fundamental en un mundo donde la comunicación, la comprensión y la correlación de fuerzas internacional es determinante para influir en los cambios y orientaciones de un estado nacional.

Sin duda, la capacidad de llamamiento a grandes estratos de la población mexicana se vincula estrechamente con su organización, su identidad, sus demandas y el conjunto de acciones emprendidas, teniendo como fondo un conflicto de enormes proporciones, y la necesidad de mirar a través de la visión de los levantados, una perspectiva que devuelva la conciencia alerta y decidida para transformar el mundo y las condiciones de vida.

$\mathrm{Su}$ fuerza de convocatoria, entonces, radica en que se nombra y emplaza a la sociedad civil a una lucha que ya iniciaron quienes así exigen, para sumarse al movimiento que está en marcha, con sus propias iniciativas y convicción de no dejarse definir y encajonar por el poder y el neoliberalismo, es decir, se convoca a tomar la propia palabra a todos aquellos que también busquen alzar la voz y decir iya basta!, dando pasos firmes hacia la propia organización social independiente.

También, como un elemento fundamental en su fuerza de convocatoria, se enlaza la historia del zapatismo revolucionario de 1910 al 1917, registrada en la memoria colectiva, y que el EZLN trae al escenario del conflicto. Convocatoria, por cierto, no igualada por movimiento alguno en el país ni en muchos otros, y que alcanza dimensiones nacionales e internacionales, por su carácter amplio, abierto e inclusivo. 


\section{La relación de consistencia}

Indica la fuerza, resistencia y firmeza del movimiento, y puede analizarse cuando establecemos el nexo entre la identidad y las demandas del EZLN. En este sentido, la pregunta central es si existe correspondencia entre lo que el movimiento declara que es, y las exigencias que proclama, esto es, entre la naturaleza del actor y las banderas de lucha que despliega.

Afirmar que el zapatismo es un movimiento consistente, implica demostrar que esa tan reconocida identidad flexible, con base en el establecimiento de una relación diferente entre presente y futuro, se conecte y vincule con las demandas indígenas y asimismo con las democráticas de alcance nacional. Que su reinvención de la identidad indígena pueda influir en el tipo de república con que el país ingresará al nuevo milenio. Es decir, si "...su actitud propositiva, constructiva e incluyente, en un siglo que termina convulsionado por problemas étnicos, lo convierte en un activo promotor del respeto universal a las particularidades, las voces y las identidades que pueblan el mundo" (Betancourt, 1998: 93).

Se trata de analizar aquí la consistencia del EZLN como resistencia, fuerza y firmeza, en la medida que las consideramos como resultado de la condición particular derivada de la unidad que forman la identidad y las demandas que enarbola como movimiento social. Y si bien la organización ocupa un lugar importante en la determinación de su fortaleza y empuje, la reflexión en este caso se circunscribe a ese vínculo fundamental que se soporta en la dialéctica entre lo que el actor declara ser y el comportamiento respectivo, y las banderas que proclama, es decir, las demandas que marcan el camino y las prioridades de la lucha.

La consistencia se refiere a ese núcleo duro del movimiento, que expresa la situación y el momento en que el ser social y su palabra se encuentran, se oponen y se arroyan mutuamente, sobreponiéndose uno a la otra alternadamente, en una trama que las hace inseparables, ya que al ser lo que se dice remite necesariamente a las demandas, y éstas permanecerán como partes de un discurso vivo, no objeto de satisfacción sino de realización. La fuerza, entonces, que adquiere el movimiento al negarse a ser de otra manera, de no aceptar algo menos que las demandas, radica en que cualquier desviación o retroceso en la posición establecida afectaría directamente la identidad, la razón de ser 
del levantamiento, trastocando esa "muralla" virtual que representa no alterar su identidad ni sus demandas, ya que, finalmente, son las dos caras de una misma moneda, donde de un lado está el símbolo de la esencia, y atrás de él la cara de la presencia en la palabra, en la letra que hizo signo, y que le da a la identidad su argumento y su coartada.

Y cuando constatamos que a casi cuatro años de la insurrección, los ecos del iya basta!, del llamado a la desobediencia y a la rebeldía identitaria suenan y resuenan aquí y más allá de las fronteras; y de que el movimiento resiste, avanza y continúa firme en sus reclamos, encontramos que esa relación entre identidad y demandas se ha revelado como una verdadera armadura contra todas las fuerzas que lo atacan; como esa amalgama que no permite el paso de las provocaciones y desviaciones pero, sobre todo, que se manifiesta como ese momento creativo, de encuentro interno y externo, entre lo conocido y lo desconocido, más allá de los compromisos formales y más acá de una historia de hermandades. Se trata, en una palabra, de algo así como un micro-sistema dentro del movimiento, que alimenta y mantiene la relación orgánica con el conflicto, asomando tanto los caracteres del sujeto que se autodefine, como los abatares de una contienda en que los enfrentamientos no permiten más que la resistencia y la fijeza de los motivos.

Por ello, se habla en este punto de la fuerza de la razón en la acción, donde así como se persiste en las demandas, se resiste en el silencio, en la búsqueda de otros interlocutores, otros escuchas que quieran saber de las historias por venir de las identidades postergadas, negadas y sometidas. Porque las demandas hablan tanto por el ser como por el devenir, en una trama de doble acción: resistir ante las fuerzas enemigas de todo tipo; y ampliar y reforzar los lazos con la sociedad civil, sus organizaciones y reacciones que retoman y reviven la identidad a través de las demandas, y éstas como voces y razones de la identidad negada se sublevan.

La relación de consistencia, en la lógica que va trazando el movimiento, cumple una función primordial: mantener en suspenso, latente y presente, la pregunta acerca de lo que es y pretende el EZLN. Un constante interrogarse desde la historicidad por aquello que no se tiene y tampoco se sabe. Un permanente encuentro esperado que está fuera del alcance; pero que se muestra como posible en la lucha, en la incertidumbre del ser, que no obstante con los acontecimientos se ha 
vuelto creíble, accesible porque el juego de fuerzas y la apuesta por el cambio así lo plantean.

El entramado que se presenta entre identidad y demandas aparece como una fuente y referencia de una identidad activa, que se refuerza, pregunta e impulsa al movimiento a luchar por las verdades, necesidades que se funden y confunden con el ser, que a su vez se busca en las demandas y obtiene en éstas sus puntos de apoyo, sus cualidades específicas y sus razones al porvenir. El producto más acabado de la fusión entre identidad y demandas es el despliegue de acciones por reivindicaciones regionales así como por banderas de lucha para el conjunto de la sociedad civil: lo particular y lo general en un solo bloque, una sola marca que no cede. Es la unión indefinida del ser que quiere decirse, y cómo es que abre su apuesta; el ser que busca con-seguir-se; negándose para afirmarse, y declarándose para luchar por el derecho a la diferencia.

\section{Relación de estructuración en el EZLN}

Esta puede observarse, siempre y cuando se constate una concordancia entre la identidad y el desempeño alcanzado. Se trata de una vía para analizar la forma en que el sujeto social toma acción en la constitución de la vida social, por lo que interesa determinar si ese ser que se autodesarrolla como actor político lo ha hecho a través de una práctica (praxis) que así lo va moldeando. De si las acciones no sólo corresponden con el decir de lo que son, en tanto zapatistas, sino en que su comportamiento sea consecuente y lleve a conformar una alternativa donde el sujeto sea parte activa de la estructuración.

Como realidad cambiante que no conocía más derroteros que los impuestos por la dialéctica del amo y el esclavo, sobre la que busca incidir el zapatismo, tiene que afrontarse con otra identidad, con aquella que aparece como contradictoria, ya que emplea las armas para terminar con la violencia, y hacer posible la creación de un espacio para el diálogo acerca del país que queremos los mexicanos, o sea, como un ejército con la vocación de dejar de serlo. Quiere decir, con una identidad que la práctica tiende a re-estructurar, pero que a la vez se mantiene como construcción, como expectativa y esperanza volcada en utopía.

El anhelo social que se desborda en utopía busca acceder a lo real con una identidad que posibilite socializar el conflicto, y los caminos 
para encontrar respuestas. Por eso también la lucha contra el poder forma parte de ese mundo contra el que los zapatistas combaten, y su concepción, por lo tanto, no se agota en buscar la expropiación de los expropiadores, sino que cuestiona la existencia de un mundo organizado sobre la base de las relaciones de poder. De ahí que la democracia, como una de las demandas centrales del zapatismo, sería la negación misma de las relaciones de poder.

Por ello, también, la construcción del mundo nuevo del que habla el EZLN, y la estructuración que supone, implica un nuevo proyecto de civilización y no una modalidad del vigente. "Por eso, además, el zapatismo entra en conflicto no solamente con las clases dominantes actuales y sus estructuras de poder, sino con la figura de clase dominante y con la idea de dominación" (Ceceña, 1998: 138).

La relación de estructuración, no es otra que la relativa a la praxis, constituyente del sujeto social, de la vida social, en tanto que forma en que todas dimensiones de la vida social se producen en el desempeño de la conducta social, por cuyo proceso se constituyen las colectividades, y se dan las modificaciones que la misma práctica implica.

En la medida que la praxis, como presentificación y actualización del ser del sujeto social que se constituye en esa acción, significa tanto la intencionalidad como la regularidad de la misma, toma sentido y orientación en cuanto que conduce a la identidad a revelarse constantemente. Y una praxis expresa la identidad que se alcanza a sí misma en el proceso, en tanto que incide en un orden a la vez simbólico y regulativo que le otorga sus dimensiones espacio-temporales y categoriales.

La estructuración, como relación lógica central en la comprensión de la praxis del sujeto, hace referencia, además, a ese nexo del actor social con el conflicto en que se inscribe, refiriendo así el hecho de que la práctica del EZLN se encuentra estructurada, es decir, reglada y simbolizada en el imaginario social, así como en la historicidad de la sociedad civil, puesto que su desempeño guarda una correspondencia particular con los rasgos de su identidad, precisamente por ese carácter de relación estructurante que ha logrado el zapatismo con su lucha.

A diferencia de las demandas que presentan la entrada al proceso y son su condición elemental, el desempeño tiene tantas caras como acciones requiera llevar a cabo el EZLN, o sea, implican una lógica 
estratégica no sólo flexible, sino también acorde con el discurso identitario, de tal manera que si un combatiente zapatista realiza una acción propagandista o bélica, al hacerlo con la razón del indígena sometido-sublevado, logra un vínculo como presencia demandante, con el conflicto del que forma parte y al que vuelve a cada momento configurando una relación ideológica y política diferente.

Resulta fundamental considerar la relación de estructuración en el análisis del movimiento social, ya que de no establecerse la congruencia entre identidad y desempeño, la praxis podría no ser estructurante, con lo cual el sujeto social carecería de su constitución como tal, sobre todo debido a que un desempeño que no se asimile como praxis correría la suerte de acciones defensivas o mecánicas que no redundan en una conciencia de la lucha.

De igual forma, si la identidad no significara acciones con un sentido claro y cierto, la praxis podría seguir su propia lógica, o sea, pasar por el margen del pragmatismo, de la verdad como utilidad, y no la verdad como premisa, que es el supuesto central de la estructuración como proceso. Entonces, si la praxis aproxima y otorga las dimensiones de espacio y tiempo al movimiento zapatista, es el medio para definir una posición como sujeto-actor en una toma de acción.

De ahí que la estructuración como sujeto social a través de la praxis, posibilite al movimiento zapatista a irrumpir, tener presencia y autoridad moral para llamar a la sociedad civil a la movilización y la desobediencia, para desde la lucha clamar por el respeto a la diferencia $\mathrm{y}$, sobre todo, una vinculación problemática con el imaginario social de la lucha por la libertad, democracia y justicia. Como sujeto social que se estructura en la praxis, a cada paso su discurso habla de su identidad, y los hechos responden por las palabras.

En la lógica de concebir la coherencia del movimiento del EZLN, la relación de estructuración permite ir a fondo en el examen de cómo la historicidad del sujeto no es otra cosa que su historia actualizada, develada, acometida como una necesidad humana, social e individual. $\mathrm{Su}$ consecución, en tanto deborde consecuente del ser en su temporalidad actuante, le da al movimiento no sólo un anclaje en el conflicto y sus complejas relaciones, sino que además crea el contexto dentro del que el actor protagoniza su acción, su toma de acción que a la vez es constitutiva. 
También puede hablarse de una estructuración deconstructiva, ya que la actualización de la identidad en la praxis tiene a cuestionar y replantear el problema de la reproducción social y de la transformación social.

\section{La relación de efectividad del movimiento}

Puede encontrarse si contrastamos las demandas enarboladas y el desempeño que ha tenido. Se trata de reflexionar en dos cuestiones: 1) qué tanto las demandas planteadas se han conseguido, y 2) cuál es el balance respecto al desempeño del movimiento en sus nexos con las peticiones que lo identificaron como nuevo sujeto social.

Si partimos de que las demandas del EZLN son tanto inmediatas y regionales como mediatas y de alcance nacional, y que su desempeño lo ha llevado a movilizar a la sociedad civil del país, así como a lograr trascendencia en tanto movimiento social que estableció un contrapeso al poder político y económico en México, la pregunta es si ha resultado efectivo: qué tanto las demandas se van actualizando en el desempeño, en qué medida éste mantiene y avanza en la conquista de las demandas, y de qué manera entre los reclamos centrales y la praxis del desempeño puede establecerse una interrelación fundamental, puesto que las primeras, a la vez que funcionan como discurso, adquieren sentido en el conflicto, y en la toma de acción por el sujeto, es como la estrategia a la que tiene que orientarse toda táctica, con una praxis consecuente, tanto como medio para alcanzar el objetivo, y vía que determina las prioridades en la lucha.

Entonces, ponderar la efectividad del EZLN implica, de una parte, hacer un balance de la racionalidad exhibida por los zapatistas en cuanto a una praxis que debe dar cuenta de las demandas planteadas. Así, el movimiento estableció desde un principio algunas condiciones particulares para luchar por las grandes banderas populares: democracia, justicia y libertad; y asimismo por un conjunto de proclamas, reivindicaciones y cambios sociopolíticos de fondo, dentro de los que sobresale la lucha por la autonomía municipal -y regional-, y las exigencias de servicios elementales, infraestructura e impulso efectivo a las culturas indígenas. Resumiendo, si analizamos las demandas del EZLN a la luz del amplio desempeño que ha mantenido desde su conformación y en la participación pública a partir de 1994, encontramos que se plantearon tres conjuntos de demandas, desde luego relacionados entre sí, y para las cuales se impulsaron acciones 
generales, particulares y específicas en la lógica de la lucha por su consecución:

a) demandas sociales, para mejorar los niveles de vida de la población indígena; en este rubro, el EZLN no sólo tuvo que imponer un estado de excepción en la zona del conflicto, lo que se conoce como una economía de guerra en las comunidades de influencia zapatista, sino que, al convertirse en un foco de descontentos, irradió su accionar directo para instrumentar un sin fin de actividades encaminadas a ese gran propósito. Algo se logró en las negociaciones con el gobierno federal; otro tanto proveniente de organizaciones sociales nacionales y extranjeras, y otro más con el esfuerzo del trabajo colectivo comunal;

b) demandas culturales, que provocaron la posterior organización nacional de los pueblos y organizaciones indígenas; la lucha política por la identidad indígena dentro de la nación, así como toda una avalancha de reclamos tendientes a reivindicar el pluralismo cultural como característica de la nación mexicana. En este aspecto, tanto los Acuerdos de San Andrés como la conocida como Ley Cocopa, resultaron en un planteamiento central para poder acceder a una nueva etapa en la historia del país; aunque, como era de esperarse, el Estado mexicano no pudo responder adecuadamente a la demanda de la sociedad civil, incumpliendo su palabra pactada en las negociaciones con el EZLN, y

c) Demandas políticas, de alcance nacional e interés común, toda vez que atañen a la lucha por la democracia, la justicia y la libertad popular, cuestionando y enfrentando abiertamente al Estado, el gobierno y las fuerzas armadas, emplazándolos, sin embargo, a efectuar un cambio profundo, o bien a responder ante los reclamos populares con una nueva actitud. En este sentido, puede hablarse de que el zapatismo no sólo ha demostrado efectividad, sino que logró ir más allá de lo que en apariencia se planteaba en un principio, transitando desde un levantamiento indígena localizado, dentro de un conflicto agudizado por el neoliberalismo en el país, a significar una corriente contestataria, de alcance mundial y que cuenta ya con toda una red de solidaridad, de activismo y de difusión de las demandas y la lucha zapatista, con lo que muestra que su desempeño no sólo es 
el brazo que realiza la acción que la demanda clama, sino que ha logrado multiplicar las acciones, abrir el panorama de las demandas, incluir otras, llevarlas y lanzarlas aquí y allá, en una tarea monumental que no parece tener otra lógica que la terca resistencia y lucha desbordante.

Como componente básico de la lógica interna del movimiento zapatista, la efectividad da cuenta de la certeza que ha alcanzado el EZLN, o sea, de la seguridad obtenida de los distintos saberes que la praxis acumula a la conciencia de la lucha, como resultante de un contraponer del movimiento sus demandas a sus esfuerzos, sus deseos a sus faltas y sus arrebatos a sus temores. Es tomar en sus manos los problemas, comprenderlos y embarcarse en el incierto camino de la lucha contra el poder, teniendo como argumento el antipoder, ¿pero, con las armas?... paradoja de nuestra historia, y motivo de los "nuevos condenados de la tierra".

Además, desde el punto de vista estrictamente lógico, es posible y factible que surjan, cambien y se diversifiquen los desempeños del EZLN, en función tanto de la participación y sentir de la sociedad civil, como del gobierno federal. Las demandas, por su parte, no han variado, y algunas empiezan ya a tomar forma en la voluntad de las comunidades. Algunas acciones significan desobediencia, fuerza comunitaria y lucha por la autonomía indígena municipal. Esto el gobierno lo considera como palabras mayores, y su rechazo es la razón del Estado contra los indígenas "manipulados".

Sin embargo, el zapatismo continúa prendiendo como una chispa en la pradera seca, ondeando las banderas de lucha y militando a favor de la organización de la sociedad civil. Su efectividad puede preguntarse por la resonancia alcanzada, y por la cascada de identificaciones a que ha dado lugar. Mientras demandas y praxis mantengan esa necesaria expectativa y exigencia, la mejor prueba de que funciona aún su razón es que se siga escuchando su voz, su discurso y su llamado.

Por lo anterior, no se trata de "medir" hasta dónde las demandas han sido satisfechas en función del desempeño registrado, sino que tanta certeza ha logrado el movimiento insistiendo en las demandas, defendiendo los acuerdos alcanzados, y acumulando fuerza en las bases de apoyo y con otros actores, es decir, si puede encontrarse que el desempeño se orienta, persigue y fundamenta las demandas lanzadas. Se refiere, en todo caso, a la lógica del sujeto social que desarrolla una 
praxis renovada, cuestionadora y desbordada, pero bajo un conjunto de banderas que representan principios sólidos para la lucha. En esa racionalidad, la efectividad del zapatismo tendría más que ver con la persistencia inflexible de la lucha que con los resultados inmediatos, ya que se trata de un proceso en el cual el zapatismo ha dado pasos gigantescos, pero su garantía no se reduce a las conquistas, que al fin de cuentas son de la sociedad civil como un todo, sino más bien a la seriedad y contundencia de las acciones, las iniciativas y propuestas para seguir por el camino de esas exigencias.

\section{Conclusiones}

1. Para impulsar los cambios sociales, políticos y culturales que el país requiere y la sociedad civil es la encargada de promover, el movimiento zapatista no sólo representa el caso más importante desde el movimiento revolucionario de 1910 a 1917, sino que además inscribe el momento del cambio de época histórica para México, al marcar la caída inevitable del sistema político capitalista-destructor de la sociedad civil, e iniciar un periodo de transformación político-constructivo de los sujetos sociales que toman acción, incluso armada, para asumir su papel en la pluralidad étnica, cultural, ideológica, social y territorial que conformamos la nación.

2. Al pasar de ser el sujeto del enunciado, para convertirse en sujeto de la enunciación, el EZLN ha elaborado el discurso más acabado, más avanzado, completo y que ha podido articular con una nueva palabra y una voz ancestral y a la vez actual, las demandas más importantes y sentidas para las comunidades chiapanecas, y para todos los pueblos del mundo que luchan contra la opresión y el olvido, pero también por encontrar un nuevo rumbo para sus utopías de nuevo siglo.

3. Desde la teoría de los movimientos sociales, en la experiencia del EZLN se encuentran dos cuestiones centrales:

a. Que analizar la coherencia y la trascendencia de un movimiento social puede permitir estudiarlo en sus dos dimensiones principales: hacia adentro, por medio del examen de su coherencia, y hacia afuera, a través del análisis de la trascendencia alcanzada. Así, el análisis de la coherencia es a la vez una categoría analítica y metodológica, puesto que la 
descomposición implica un aislamiento de cada parte considerada, y la posibilidad de contrastarla, diferenciarla y relacionarla con las otras partes, logrando así identificar los posibles factores causales, pero sobre todo un esquema de análisis lógico a partir del cual poner en acción los hechos y acontecimientos del movimiento e interpretarlos con fundamento.

b. Del análisis de la coherencia y trascendencia, sobresalen los siguientes puntos:

i) La organización del EZLN aparece como la base y estructura del movimiento, ya que su función es de soporte, disposición de fuerzas y recursos, división del trabajo, procesamiento y conformación de las acciones, así como de articulación de individuos, para constituirlos en un sujeto colectivo y actor político de nuevo tipo.

ii) Una identidad flexible, pero basada en principios e ideologías que tengan fundamento y respondan a la organización, las demandas y el desempeño requerido, favorece que un movimiento social pueda asumir una posición auténtica y a la vez propositiva de cambios sociales generales y particulares, ya que puede sustentar un conjunto de demandas para la lucha; e impulsar una praxis que actualice el conflicto y le permita al movimiento un autodesarrollo y lograr trascendencia.

iii) El desempeño del EZLN demuestra no sólo la gran capacidad de irradiar su fuerza, convencer, atraer y activar descontentos, sino que también subraya la necesidad de conformar a los movimientos sociales como flexibles redes de solidaridad e interacción a nivel ético-político, sobre la semilla de una praxis consecuente como el camino para combinar la radicalidad con la disposición al diálogo, la entrega comprometida a una lucha con las iniciativas para cambiar la organización social.

c. Una gran lección del zapatismo de fin de siglo es que los movimientos sociales pueden ser las formas de organización y acción social más importantes, por medio de las cuales sea factible avanzar hacia transformación social, sobre todo porque su consistencia y trascendencia contribuyen a la constitución de 


\title{
los sujetos sociales encargados de los cambios, cuyas demandas brotan por doquier a cada momento.
}

\author{
Email:aranda@coatepec.uaemex.mx
}

\section{Bibliografía}

Betancourt, A. (1998), "El zapatismo: la intervención de una modernidad alternativa", en Kanoussi, D. (comp.) El zapatismo y la política, México: Plaza y Valdez.

Ceceña, A. (1998), "De cómo se construye la esperanza", en revista Chiapas, núm. 6, México: IIE-UNAM.

Consejo de Población del Estado de México (1995), "Grado e indice de marginación de México", con base en el Conteo de Población 1995, versión preliminar.

Díaz-Polanco, H. (1997), La rebelión zapatista y la autonomía, México: Siglo XXI Editores.

Esteva, G. (1994), Crónica del fin de una era, México: Posada.

EZLN (1994), La palabra de los armados de verdad y fuego. Entrevistas, cartas y comunicados (hasta el 4 de marzo de 1994), México: Fuenteovejuna.

(1996), Documentos yComunicados

Gilly, A. (1997), "Chiapas la razón ardiente”, en Ensayo sobre la rebelión del mundo encantado, México: Era.

Holoway, J. (1997), "La revuelta por la dignidad”, en revista Chiapas, núm 5, México: IIE-UNAM. (1996), “La resonancia del zapatismo”, en revista Chiapas, núm 3, México: IEE-UNAM.

Kanoussi, D. (1998), "El zapatismo y la política de la identidad", en Kanoussi, D (comp.) El zapatismo y la política, México: Plaza y Valdéz.

Machuca, J.A. (1998), "La democracia radical: originalidad y actualidad política del zapatismo de fin del siglo XX", en op. cit, Kanoussi, D. El zapatismo....

Melucci, A. (1998), "Acción colectiva y transformación personal en la era de la información", en revista Ciudades, núm 37, enero-marzo, México: RNIU.

Mendez, L. y Cano, A. (1994), La guerra contra el tiempo, México: Espasa Calpe.

Nolasco, P. (1997), "Cambio político, estado y poder: un acercamiento a la posición zapatista", en revista Chiapas, núm. 5, México: IEE-UNAM.

Rodríguez, O. (1997), "EZLN, un balance a tres años", en Gutiérrez, E. (coord. gral.) El debate nacional, núm. 4, Los Actores Sociales, México: UdeG-Diana.

Santillana, A. (1996), "FZLN: expresión política del antipoder", en revista Viento del Sur, núm. 6, Primavera, 1996.

Tello, C. (1995), La rebelión de las cañadas, México: Cal y Arena.

Tiguera, S. (1995), "El zapatismo y la democracia popular en nuestra América", en varios autores, Chiapas insurgente, Navarra, España: Edit. Txalaparta. 